National

\title{
NAS-NS
}

3102

Academy

of

Sciences

National Research Council

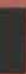

NUCLEAR SCIENCE SERIES

Radiochemical Techniques

Separations by

\section{Solvent Extraction with}

Tri-n-octylphosphine Oxide

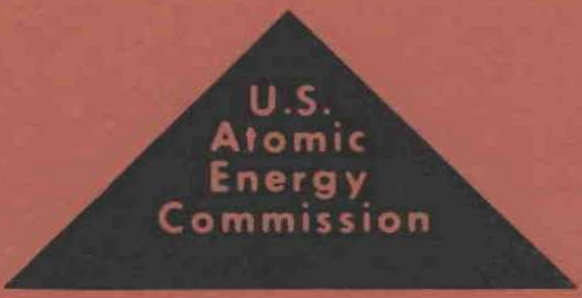




\section{COMMITTEE ON NUCLEAR SCIENCE}

L. F. CURTISS, Chairman

National Bureau of Standards
ROBLEY D. EVANS, Vice Chairman

Massachusetts Institute of Technology

J. A. DeJUREN, Secretary

Westinghouse Electric Corporation

C. J. BORKOWSKI

Oak Ridge National Laboratory

ROBERT G. COCHRAN

Texas Agricultural and Mechanical

College

SAMUEL EPSTEIN

California Institute of Technology

U. FANO

National Bureau of Standards

HERBERT GOLDSTEIN

Nuclear Development Corporation of America
J. W. IRVINE, JR.

Massachusetts Institute of Technology

E. D. KLEMA

Northwestern University

W. WAYNE MEINKE

University of Michigan

J. J. NICKSON

Memorial Hospital, New York

ROBERT L, PLATZMAN

Laboratoire de Chimie Physique

D. M. VAN PATTER

Bartol Research Foundation

\section{LIAISON MEMBERS}

PAUL C. AEBERSOLD

Atomic Energy Commission

J. HOW ARD MCMILLEN

National Science Foundation
CHARLES K. REED

U. S. Air Force

WILLIAM E. WRIGHT

Office of Naval Research

\section{SUBCOMMITTEE ON RADIOCHEMISTRY}

W. WAYNE MEINKE, Chairman

University of Michigan

GREGORY R. CHOPPIN

Florida State University

GEORGE A. COWAN

Los Alamos Scientific Laboratory

ARTHUR W. FAIRHALL

University of Washington

JEROME HUDIS

Brookhaven National Laboratory

EARL HYDE

University of California (Berkeley)
HAROLD KIRBY

Mound Laboratory

GEORGE LEDDICOTTE

Oak Ridge National Laboratory

JULIAN NIELSEN

Hanford Laboratories

ELLIS P. STEINBERG

Argonne National Laboratory

PETER C. STEVENSON

University of California (Livermore)

LEO YAFFE

McGill University

\section{CONSULTANTS}




\section{DISCLAIMER}

This report was prepared as an account of work sponsored by an agency of the United States Government. Neither the United States Government nor any agency Thereof, nor any of their employees, makes any warranty, express or implied, or assumes any legal liability or responsibility for the accuracy, completeness, or usefulness of any information, apparatus, product, or process disclosed, or represents that its use would not infringe privately owned rights. Reference herein to any specific commercial product, process, or service by trade name, trademark, manufacturer, or otherwise does not necessarily constitute or imply its endorsement, recommendation, or favoring by the United States Government or any agency thereof. The views and opinions of authors expressed herein do not necessarily state or reflect those of the United States Government or any agency thereof. 


\section{DISCLAIMER}

Portions of this document may be illegible in electronic image products. Images are produced from the best available original document. 


\section{Separations by Solvent Extraction with Tri-n-octylphosphine Oxide}

J. C. WHITE and W. J. ROSS

Oak Ridge National Laboratory

Oak Ridge, Tennessee

February 8, 1961

Reprinted by the Technical Information Center

U. S. Department of Energy

Subcommittee on Radiochemistry

National Academy of Sciences - National Research Council 


\section{FOREWORD}

The Subcommittee on Radiochemistry is one of a number of subcommittees working under the Committee on Nuclear Sclence within the National Academy of Sciences - National Research Counc1l. Its members represent government, industrial, and university laboratories in the areas of nuclear chemistry and analytical chemistry.

The Subcommittee has concerned itself with those areas of nuclear sclence which involve the chemist, such as the collection and distribution of radiochemical procedures, the establishment of specifications for radiochemically pure reagents, avallability of cyclotron time for service irradiations, the place of radiochemistry in the undergraduate college program, etc.

This serles of monographs has grown out of the need for up-to-date compliations of radiochemical information, procedures, and techniques. The subcommittee has endeavored to present a series which will be of maximum use to the working sclentist and which contains the latest avallable information. Each monograph collects in one volume the pertinent information required for radiochemical work with an individual element or with a specialized technique.

An expert in the particular radiochemical technique has written the monograph. The Atomic Energy Commission has sponsored the printing of the series.

The Subcommittee is confident these publications will be useful not only to the radiochemist but also to the research worker in other fields such as physics, biochemistry or mediolne who wishes to use radiochemical techniques to solve a specific problem.

W. Wayne Me1nke, Chalrman

Subcommittee on Radiochem1stry 


\section{INTRODUCTION}

This volume which deals with separations by solvent extraction with tri-n-octylphosphine oxide is the second in a series of monographs on radiochemical techniques which will parallel the series on the radiochemistry of the elements. The same general style is used in both series of monographs, beginning with general reviews of the technique, then a discussion of the principles involved, a detailed survey of applications to different systems, and finaliy a collection of selected procedures which use this technique as reported in the literature.

Th1s second series of techniques monographs will cover a number of radiochemical techniques which have not been reviewed elsewhere. Plans include revision of these monographsperiodically as new information and procedures warrant. The reader is therefore encouraged to call to the attention of the author any published or unpublished material on extraction with tri-n-octylphosphine oxide which might be included in a revised version of the monograph. 


\section{CONTENTS}

Introduction .................... iv

General Considerations

Diluents .................. . . . . 2

Oxidation State of the Element ........... 2

Type and Concentration of Acid ............. 2

Concentration of Metal and Extractant ......... 3

Phase volumes. . . . . . . . . . . . . . 3

Temperature .................. . . . . . 4

Phase Equilibration ................. . . 4

Stripping ................. . . . . . 4

Decomposition of Metal Adducts ............ . . 4

Determination of Extracted Elements . . ..... 5

Extraction Characteristics

Water ..................

Inorganic Acids . . . . . . . . . . . . . . . . . 5

Extraction of Elements in Periodic Group I. . . . . . . . 8

Extraction of Elements in Periodic Group II . . . . . . . 8

Extraction of Elements in Periodic Group III . . . . . . 10

Extraction of Elements in Periodic Group IV . . . . . . 10

Extraction of Elements in Periodic Group V . . . . . . . 21

Extraction of Elements in Periodic Group VI . . . . . . 26

Extraction of Elements in Periodic Group VII . . . . . . 31

Extraction of Elements in Periodic Group VIII . . . . . 33

Extraction of the Rare-Earth Elements. . . . . . . 35

Extraction of Thorium ............. . . . 39

Extraction of Uranium . . . . . . . . . . . . . 44

Extraction of Transuranic Elements . . . . . . . 49

Appendix I

Methods for the Determination of Elements After

Extraction with Tri-n-octylphosphine Oxide ... 53

References .................. 55 


\title{
Separations by Solvent Extraction with Tri-n-octylphosphine Oxide
}

\author{
J. C. WHITE and W. J. ROSS \\ Oak Ridge National Laboratory \\ Oak Ridge, Tennessee
}

This report is a compilation of the extraction data that have been obtained for tri-n-octylphosphine oxide, $\left(\mathrm{C}_{8} \mathrm{H}_{17}\right)_{3} \mathrm{PO},(\mathrm{TOPO})$. Numerous publications are available on specific extraction characteristics of this compound. Most of these reports are included in the appendix. Although the object of most investigations on mOPO has concerned solvent extraction of essentially macro quantities of non-radioactive species, the data presented should prove of interest and potential applicability to radio nuclides also. It is the primary intent of this report to make available in a single report the extraction characteristics of TOPO.

Tri-n-octylphosphine oxide is comercially available in a relatively pure form in both the United States and Great Britain. The compound is highly resistant to oxidation and considered to be the most stable of the organo-phosphorous family. The white, waxy crystals melt at $51-52^{\circ} \mathrm{C}$ and boil at $200^{\circ} \mathrm{C}$ at $0.1 \mathrm{~mm} \mathrm{Hg}$. It is soluble in most hydrocarbons; the maximum solubility in cyclohexane at $25^{\circ} \mathrm{C}$ is 0.9222 moles per liter. (17) The solubility increases only slightly at temperatures above $25^{\circ} \mathrm{C}$.

The compound can be used as received for the vast majority of cases. Further purification can be achieved by recrystallization from cyclohexane or ethyl ether. 
Diluents. Cyclohexane is preferred as a diluent for trialkylphosphine oxides because of its very low miscibility with water and because of its excellent spectral characteristics. Kerosene, Varsol, or benzene are also satisfactory as diluents, although the solubility of water is slightly greater in these solvents than in cyclohexane. Carbon tetrachloride is useful as a diluent when inversion of the phases is desired; however, the extraction coefficients of uranium(VI), Iron(III), and chromium(VI) have been observed to be considerably less in carbon tetrachloride systems than in systems that contain kerosene or cyclohexane. Polar solvents are not appropriate because of their miscibility with water and their detrimental effects on the basicity of the phosphoryl groups.

oxidation state of the element. In general, the highest oxidation state of an element forms the most extractable species in acid-phosphine oxide systems. Arsenic(V) was the only exception observed among those elements that were investigated quantitatively. The extractability of lower oxidation states differs materially among these elements. Arsenic(III) and antimony(III) are extracted from chloride solutions as the adducts of trivalent elements; $\operatorname{tin}(I I)$ is completely oxidized to tin(IV) and extracted from chloride solutions; uranium(IV) is extractable from chloride media but is easily oxidized to uranium(VIj in acid systems unless air is excluded; iron(II) is not extracted from chloride media but is partially oxidized to the extractable trivalent oxidation state; chromium(III) and vanadium(IV) remain unoxidized and are not extracted.

Type and concentration of acid. The extractability of elements with phosphine oxides is primarily dependent on the chemical equilibria of the aqueous phase and the availability of extractable species. These factors are most favorable in acidic chloride solutions in which the acid or chloride concentration is greater than $3 \underline{M}$. Extremely large extraction coefficients are achieved with some elements in dilute (0.5 to $2 \underline{\mathrm{M}}$ ) nitric acid systems; however, the extractions of metal nitrate adducts are 
usually decreased at higher nitric acid concentrations because of partial saturation of the phosphine oxide with the acid itself. Co-extraction of nitric acid is diminished when the nitrate concentration of an aqueous solution is increased by the addition of nitrate salts rather than with nitric acid. Most of the elements are extracted to a much lesser degree from sulfuric acid solutions than from chloride or nitrate media; titanium(IV) and chromium(VI) are the principal exceptions to this trend. Perchlorate systems are not attractive for analytical separations because metal-perchlorate adducts are less soluble than those of the other mineral acids in cyclohexane solutions of phosphine oxides.

Enhancement of extraction from unfavorable acid media can usually be achieved by the addition of nitric or hydrochloric acids or salts of these acids.

Concentration of metal and extractant. The stolchlometry of the species extracted by TOPO or TEHPO from chloride solutions is indicative of adducts of the composition $\mathrm{M}^{+\mathrm{n}_{\mathrm{Cl}}} \mathrm{I}_{\mathrm{n}} \cdot 2$ (TOPO). Stoichiometric amounts of the element cannot be extracted quantitatively by a given amount of phosphine oxide because of coextraction of mineral acid; however, the phosphine oxide can be saturated by equilibration with solutions that contain an excess of the element. The concentration of extractant is limited to the solubility of the phosphine oxide in the various diluents. The solubility of TOPO varies with temperature and is $0.21,0.43,0.92,0.93 \mathrm{M}$ in cyclohexane at $6.5,11,25$, and $35^{\circ} \mathrm{C}$. For practical purposes, the maximum concentration of phosphine oxide is limited to $0.2 \mathrm{M}$ for extractions at room temperature.

Phase volumes. Equlibration is most readily attained in systems where the phase volumes are small; however, the extraction of many elements is not seriously affected when the aqueous/organic ratio is increased from I to 20 . Phase separation of cyclohexane systems are essentially instantaneous when the phase ratio is 1 and the acidity of the aqueous phase is >3. In systems where the acid concentration is lower, or where the phase 
ratio, aqueous/organic, is high, clarification of the aqueous phase may be delayed unless centrifugation is used.

Temperature. Essentially all of the data reported in this paper were obtained at room temperature $\left(20\right.$ to $\left.30^{\circ} \mathrm{C}\right)$. Although higher concentrations of extractant can be obtained at elevated temperature, the limited data available show that an inverse relationship exists between extraction coefficient and temperature. In systems that contain TOPO in the organic phase and hydrochloric, nitric, sulfuric, or phosphoric acids in the aqueous phase, the extraction coefficient of uranium decreases by one-half per ten-degree temperature rise between 20 and $50^{\circ} \mathrm{C}{ }^{(1)}$

Phase equilibration. Extraction of metal adducts in chloride or nitrate systems is essentially complete within 10 minutes under optimum conditiors, although many elements such as iron(III), molybdenum(VI), tin(IV), and uranium are extracted nearly instantaneously.

Stripping. Adducts of extractable elements exhibit varying stability toward removal of the element from the organic phase by back-extraction into an aqueous solution. Such stripping processes are most favorable with the use of acid solutions because hydrolysis of the metal salt is minimized. No suitable method has been developed for the stripping of $\operatorname{tin}($ IV) or chromium(VI), even after reduction of chromium to the trivalent oxidation state. The following solutions have been used successfully to back-extract other elements from cyclohexane solutions of TOPO:

$$
\begin{aligned}
& \text { Titanium } \quad-0.2 \mathrm{M} \mathrm{NaF} \\
& \text { Iron(III) } \quad-0.3 \mathrm{M} \mathrm{H}_{2} \mathrm{SO}_{4} \text { or } 3 \mathrm{M} \mathrm{H}_{2} \mathrm{SO}_{4} \\
& \text { Zirconium - } 1 \text { M HF } \\
& \text { Molybdenum } \quad-2 \mathrm{M} \mathrm{NH}_{4} \mathrm{OH} \\
& \text { Bismuth } \quad-7 \underline{\mathrm{M}} \mathrm{HWO}_{3} \\
& \text { Thorium } \quad-0.3 \mathrm{M} \mathrm{H}_{2} \mathrm{SO}_{4} \\
& \text { Uranium } \quad-0.2 \underline{\mathrm{M}} \mathrm{Na}_{2} \mathrm{CO}_{3} \text { or } 0.3 \mathrm{M} \mathrm{H}_{2} \mathrm{SO}_{4} \\
& \text { Decomposition of metal adducts. The phosphine oxide adduct of metal }
\end{aligned}
$$
salts can be decomposed by repeated evaporations from nitric acid and then 
from nitric-perchloric acid solutions. The residual metal-phosphates vary in the ease with which they are dissolved by mineral acids. Consequently, this method for the recovery of an extracted element is not used whenever another method is available or when the element can be determined in the organic phase.

\section{Determination of extracted elements. Radioactive isotopes are}

detected in the organic phase of phosphine oxide systems by the same methods used in aqueous solutions. Such detections are most readily achieved with gamma-emitting isotopes since the activity of allquots of the phases can be measured with a well-type scintillation counter.

Spectrophotometric methods have been developed for the determination of all elements, except arsenic and antimony, that are completely extractable with TOPO. In addition, uranium can be determined in the organic phase by fluorometric methods. These methods are listed in Appendix I. Extraction Characteristics

Water and Inorganic Acids

Water. Water is essentially immiscible (0.015 g water saturates $100 \mathrm{~g} \mathrm{C}_{6} \mathrm{H}_{12}$ at $28^{\circ} \mathrm{C}$ ) with cyclohexane solutions of TOPO and, therefore, is not transferred to the organic phase during extraction of aqueous solutions. Less than $1 \mathrm{mg}$ of water per $\mathrm{ml}$ can be detected in the organic phase, with Karl Fischer reagent, after five $\mathrm{ml}$ of $0.1 \mathrm{M}$ TOPO is shaken for 10 minutes with $5 \mathrm{ml}$ of water or 1 to $7 \mathrm{M} \mathrm{HCl}, \mathrm{H}_{2} \mathrm{SO}_{4}, \mathrm{HClO}_{4}$ or $\mathrm{HNO}_{3}$ and allowed to stand for one hour. The volumes of the two phases, therefore, remain constant throughout the extraction.

Inorganic acids. Tri-n-octylphosphine oxide in cyclohexane functions as an extractant only from acidic solutions. Mineral acids themselves are extracted with TOPO to varying degrees (Figure 1).

The acids fall into two groups on the basis of extent of extraction, i.e. the slopes of the extraction curves for hydrochloric, sulfuric, and phosphoric acids are similar but differ from those for nitric and perchloric acids. The mole ratio of acid to TOPO is less than 1 for the 
heavy, polybasic acids but is greater than 2 for hydrochloric and nitric acid.

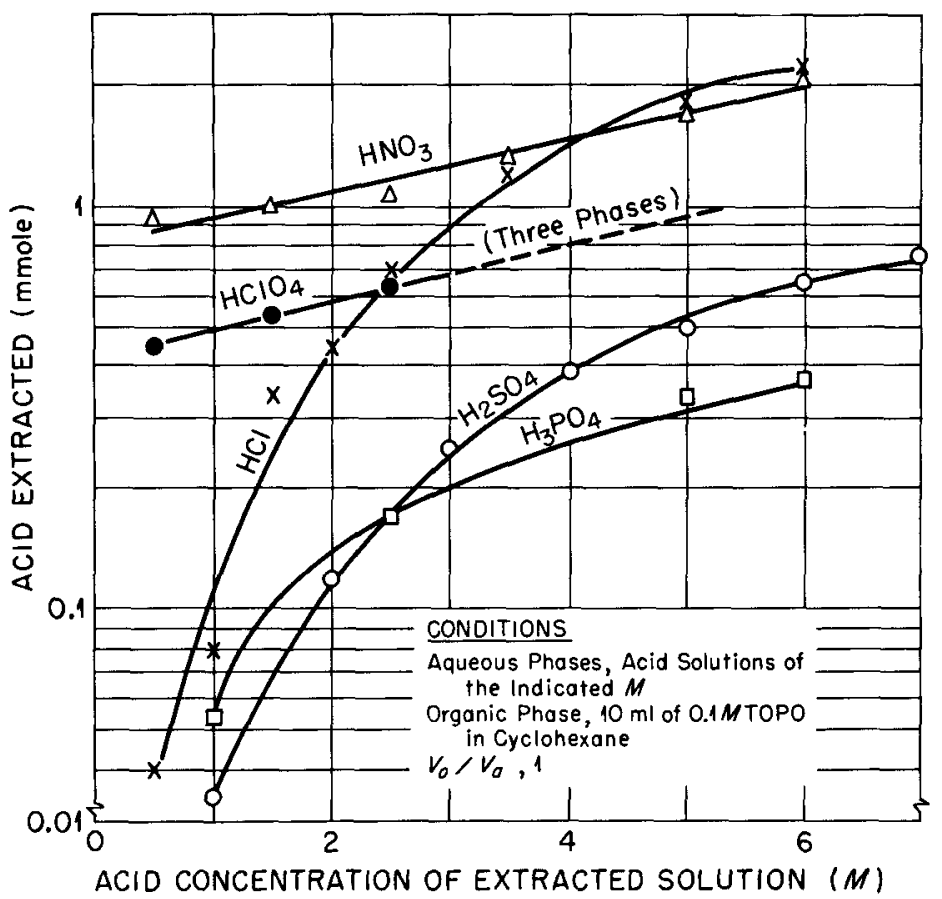

FIGURE 1. EXIRACTION OF MINERAL ACIDS FROM AQUEOUS SOLUTIONS WITH TRI-N-OCTYIPHOSPHINE OXIDE

In systems where the ionic strength of the aqueous phase is $2 \mathrm{M}$ and the concentration of TOPO in the organic phase is less than $0.4 \mathrm{M}$, the distribution behavior of nitric acid is consistent with first power dependency on the TOPO concentration. When the ionic strength is reduced below $I M$ the ratio of TOPO to nitric acid in the organic phase continually increases to values greater than 1 (Figure 2). (17)

The degree of extraction of a more extractable acid is enhanced by the addition of a less extractable acid to the aqueous phase. In nitric acid-sulfuric acid systems (Figure 3), the addition of sulfuric acid to $1 \mathrm{M} \mathrm{HNO}_{3}$ systems results in increased extraction of nitric acid to degrees similar to those achieved by increasing the nitric acid concentration in the aqueous phase. Sulfuric acid is not extracted from such mixed-actd systems that contain less than $6 \mathrm{M} \mathrm{H}_{2} \mathrm{SO}_{4}$. 


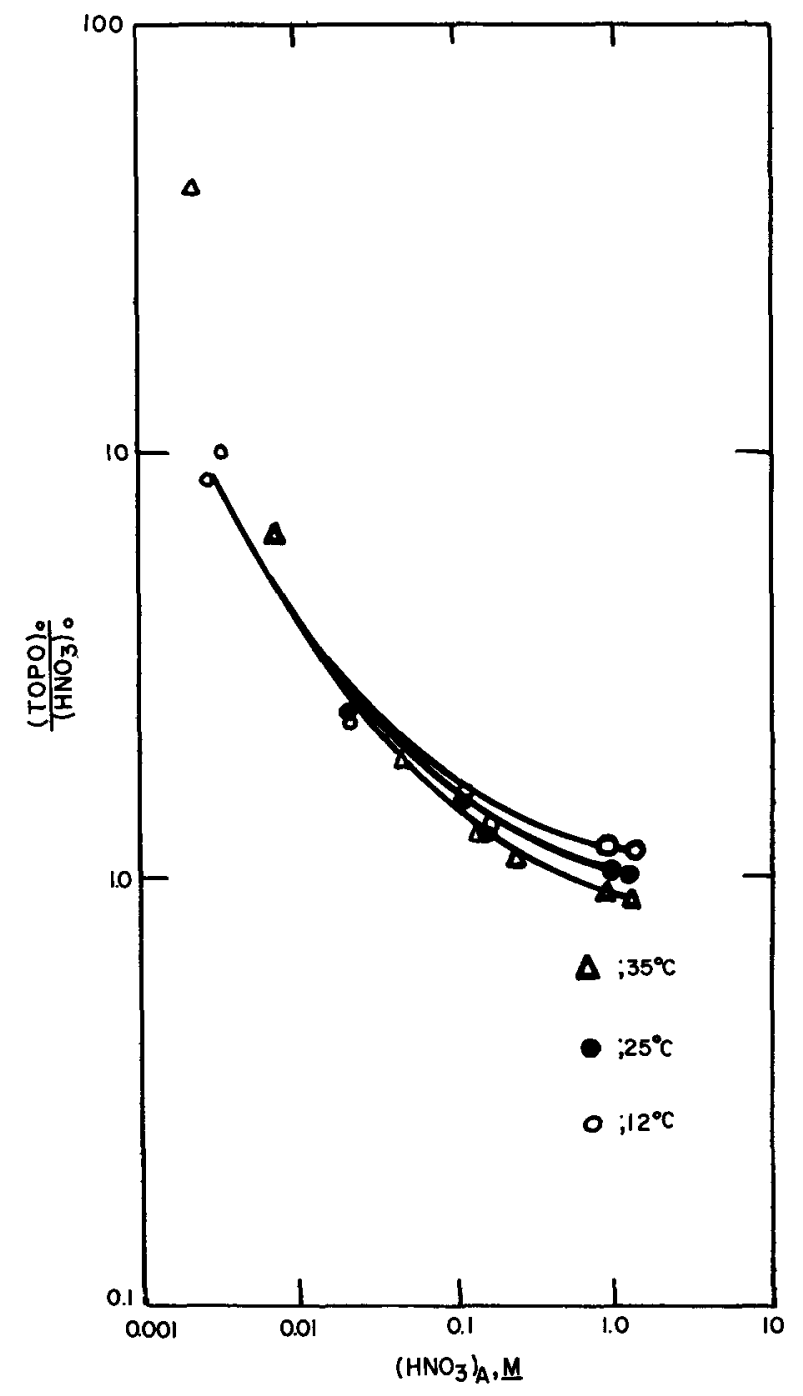

FIGURE 2. RATIO OF ORGANIC REAGENT TO NITRIC ACID CONCENTRATION IN CYCLOHEXANE SOLUTION AS A

FUNCTION OF EQUILIBRIUM AQUEOUS ACIDITY

FIGURE 3. EXTRACTION OF NITRTC AND SULFURIC ACIDS WITH TRI-N-OCTYLPHOSPHINE OXIDE AS A FUNCTION OF SULFURIC ACID CONCENTRATION. TOPO $0.1 \mathrm{M}$ in cyclohexane, $15 \mathrm{ml} ; \mathrm{HNO}_{3}$ $1 \mathrm{~N},-15 \mathrm{ml}$; Phase ratio -1 ; and Extraction time - 10 minutes.

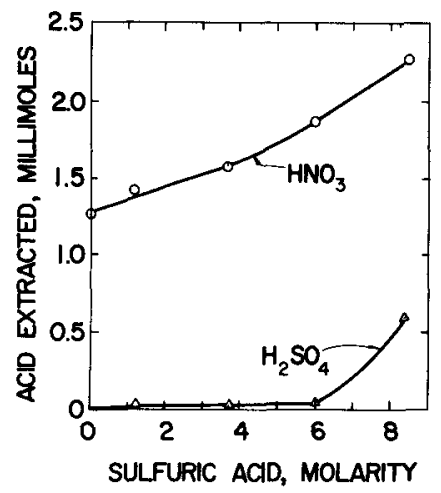


The solubility of the TOPO-acid adduct in the cyclohexane phase varies with the actd used. The perchloric acid adduct becomes immiscible in systems that contain $3 \mathrm{M} \mathrm{HClO}_{4}$ or greater and forms an intermediate, third phase. A third phase is also produced when the concentration of sulfuric acid exceeds $8 \mathrm{M}$. Nitric and hydrochloric acids form adducts that are completely soluble in cyclohexane and represent the systems most favorable for the extraction of cationic substances.

The absorption spectrum of a cyclohexane-TOPO-acid solution is important since many of the applications of this reagent involve direct absorbancy measurements in the organic phase. The spectra of cyclohexane and the adducts of hydrochloric, sulfuric, and nitric acids are given in Figure 4 over the wavelength range from 190 to $300 \mathrm{~ms}$. Only the nitric acid adduct exhibits absorption maxima in this region. These adducts do not adsorb light in the visible or near-infrared regions. In the infrared region the characteristic phosphoryl frequency at $8.8 \mu$ is shifted to slightly higher wavelengths when an inorganic acid is coordinated with the $-P=0$ group.

Extraction of Elements in Periodic Group I. The alkali metals (lithium, sodium, and potassium) are not extracted from acid solutions with cyclohexane solutions of TOPO. Consequently, neutral salts of these elements can be utilized to achieve increased extraction of other elements through a "salting-out" effect.

Copper(II) is partially extracted from $7 \mathrm{M} \mathrm{HCl}$, but not from $1 \mathrm{M} \mathrm{HCl}$ or 1 to $7 \mathrm{M} \mathrm{H}_{2} \mathrm{SO}_{4}, \mathrm{HClO}_{4}$, or $\mathrm{HNO}_{3}$.

Silver(I) is not extracted with TOPO.

Gold(III) is very readily extracted from acid chloride solutions even in the presence of sulfate, nitrate, or perchlorate.

Extraction of Elements in Periodic Group II. Beryllium, magnesium, calcium, strontium and barium are not extracted from acid solutions with TOPO.

Zinc is the only element in Group IIB that has been investigated quantitatively. This element is not extracted from acid nitrate or sulfate 


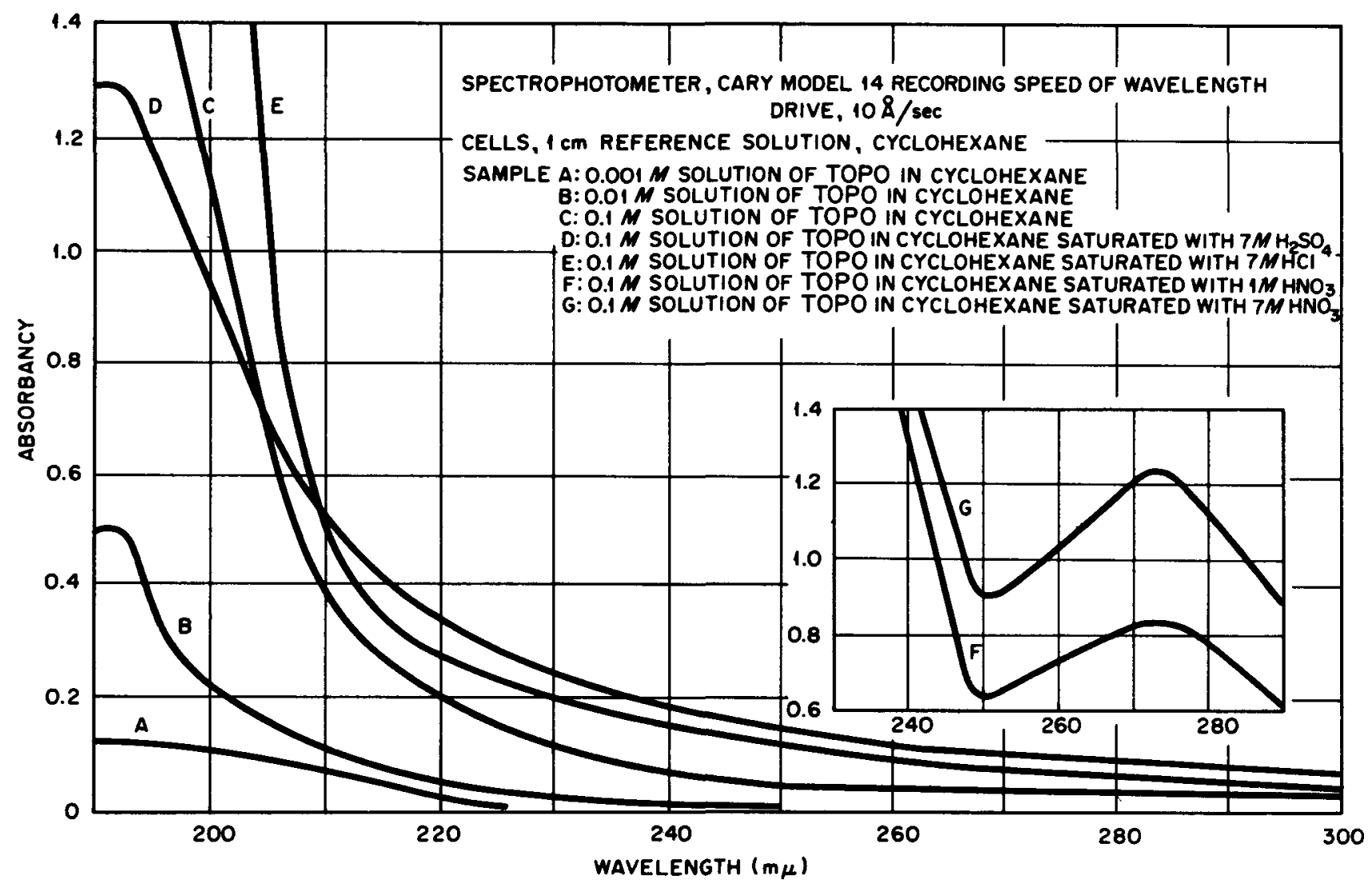

FIGURE 4. ULTRAVIOLET ABSORPITON SPECTRA OF CYCLOHEXANTE TRI-N-OCTYIPHOSPFINE OXIDE-ACID SOLUIIONS 
solutions in the absence of chloride. The extraction of zinc from hydrochloric acid or hydrochloric-sulfuric acid solution is dependent on the concentration of acid in the aqueous phase (Figure 5) and the concentration of zinc present (Figure 6). A bulky, white precipitate forms in zinc chloride-TOPO systems under various conditions as shown by the dotted lines in Figure 6. This precipitate consists primarily of TOPO and collects at the interface of the two phases, thereby preventing the determination or recovery of zinc in the organic phase.

Cadmium and mercury(II) are extracted to a very slight extent from acid chloride solutions, but not from other inorganic acids.

Extraction of Elements in Periodic Group III. Yttrium and lanthanum

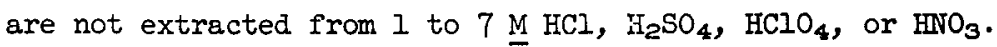

The known extraction characteristics of the IIIB elements are based on qualitative spectrographic data obtained from systems that contained $2 \mathrm{mg}$ of each element. These results indicate that boron and aluminum are not extracted from 1 to $7 \mathrm{M} \mathrm{HCl}, \mathrm{H}_{2} \mathrm{SO}_{4}, \mathrm{HClO}_{4}$, or $\mathrm{HNO}_{3}$.

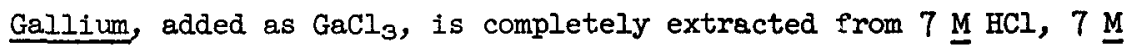
$\mathrm{H}_{2} \mathrm{SO}_{4}$ or $7 \underline{\mathrm{M} \mathrm{HClO}} 4$, but is not extracted from $\mathrm{I} \underline{\mathrm{M}}$ solutions of these acids or from 1 or $7 \underline{\mathrm{M}} \mathrm{HNO}_{3}$.

Two mg of indium, as $\mathrm{InCl}_{3}$, is extracted from hydrochloric, sulfurlc, and perchloric solutions, but not from nitric acid.

The detrimental effect of nitric acid on the extraction of these Group III chlorides is due to the high extractability of this acld itself. Extraction of Elements in Periodic Group IV. Titanium(IV) ${ }^{(4)}$ is extracted from either strong sulfuric or hydrochloric acid solutions (Figure 7). The extraction is enhanced as the concentration of each acid is increased; however, a third phase forms in $8 \mathrm{M} \mathrm{H}_{2} \mathrm{SO}_{4}$ systems. This intermediate phase is primarily an adduct of sulfuric acid and TOPO incorporated with water, cyclohexane, or both. The extractability of titanium is not affected by the presence of tartaric acid in the aqueous phase; consequently, this reagent may be used to mask other interfering elements. 


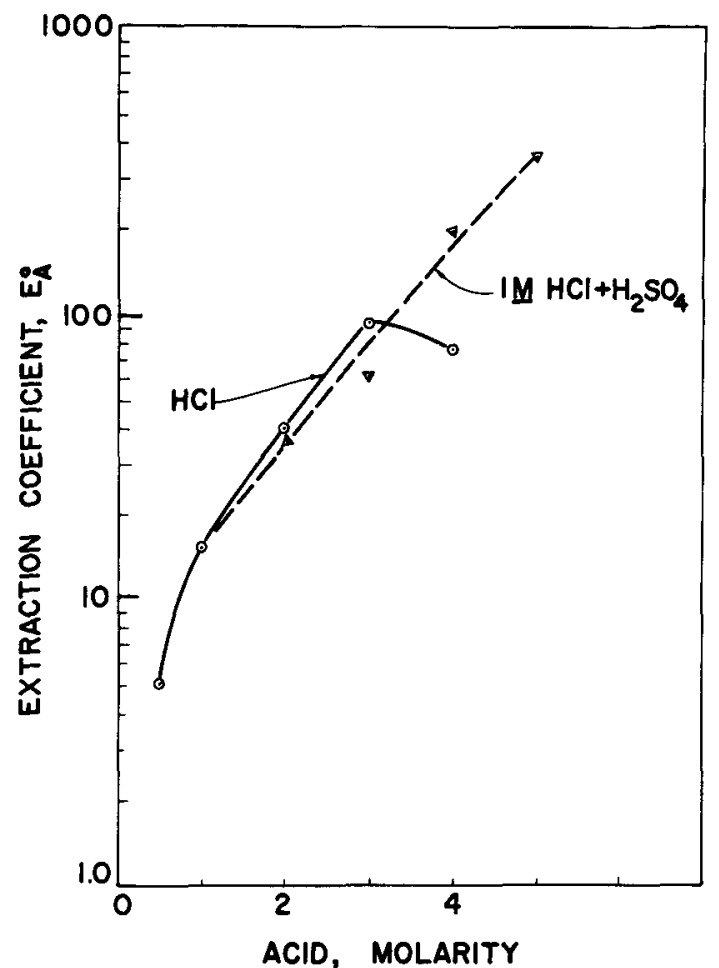

FIGURE 5. LFFECT OF AGID COICDTMRATION ON ?LE EXTRICTION OF ZINC WTII TRI-NTDCTILFOSPHINE OXIDI. Zine - 5 ng; TOPO 0.1 M cyclohexane, $5 \mathrm{nl}$; Phase ratio - 1; and Extraction time - 10 minutes.

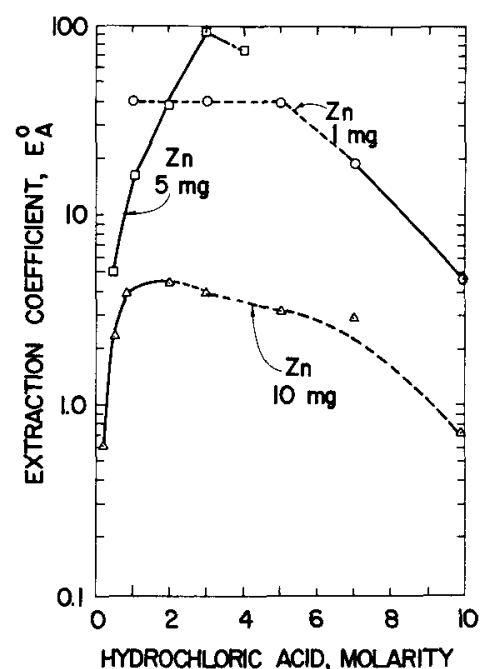

FIGURE 6. EXTRACTION OF ZINC WITH TRI-N-OCTYLPHOSPHTNE OXIDE AS A FUNCTION OF HYDROCHLORIC ACID CONCENTRATION. TOPO - $0.1 \mathrm{M}$ cyclohexane, $5 \mathrm{ml}$; Phase ratio - 1; and Extraction time - 10 minutes. 
As much as $19 \mathrm{mg}$ of titanium can be extracted in 20 minutes to a degree that exceeds 95 per cent when the aqueous phase is $6 \mathrm{M}_{2}$ in $\mathrm{H}_{2} \mathrm{SO}_{4}$ and the organic phase contains 1 millimole of TOPO. A constant amount, 0.6 mill1moles, of sulfuric acid is extracted from $6 \mathrm{M} \mathrm{H}_{2} \mathrm{SO}_{4}$ regardless of the concentration of titanium in the aqueous phase. The extracted species is postulated to be $\mathrm{THOSO}_{4} \cdot 2(\mathrm{TOPO})$ in sulfuric acid systems.

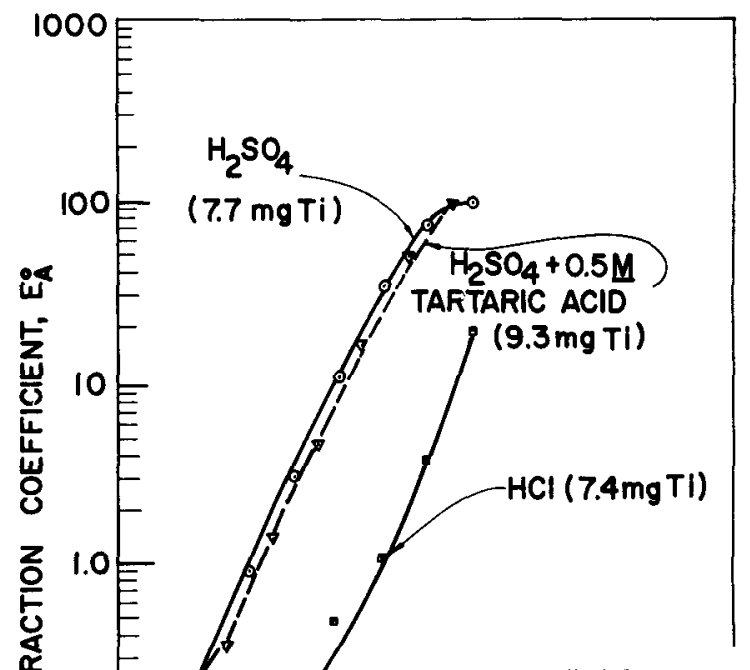

FIGURE 7. EXTRACTION OF TITANIUMI(IV) WITH TRI-N-OCTYLPHOSPHINE OXIDE AS A FUNCTION OF ACID CONCENTRATION. TOPO - $0.1 \mathrm{M}$ in cyclohexane, $10 \mathrm{ml}$; Phase ratio - 1 ; and Extraction time - 20 minutes.

Zirconium $^{(15)}$ is extracted readily from acid chloride or nitrate solutions. Concentrations of chloride or nitrate that are favorable for complete extraction of zirconium can be achieved by adjusting the acidity (Figure 8), or the ionic strength (Figures 9 and 10). Extraction equil1brium is not attained in systems of low chloride concentration as rapidzy as in nitrate media. Ten-minute extraction periods are sufficient, however, to extract zirconium from solutions that are $7 \underline{M}$ in $\mathrm{HCl}$ or $1 \underline{M}$ in $\mathrm{HCl}$ and $2 \mathrm{M}$ in $\mathrm{AlCl}_{3}$.

Zirconium is also extracted, to a lesser extent, from perchloric acid; 


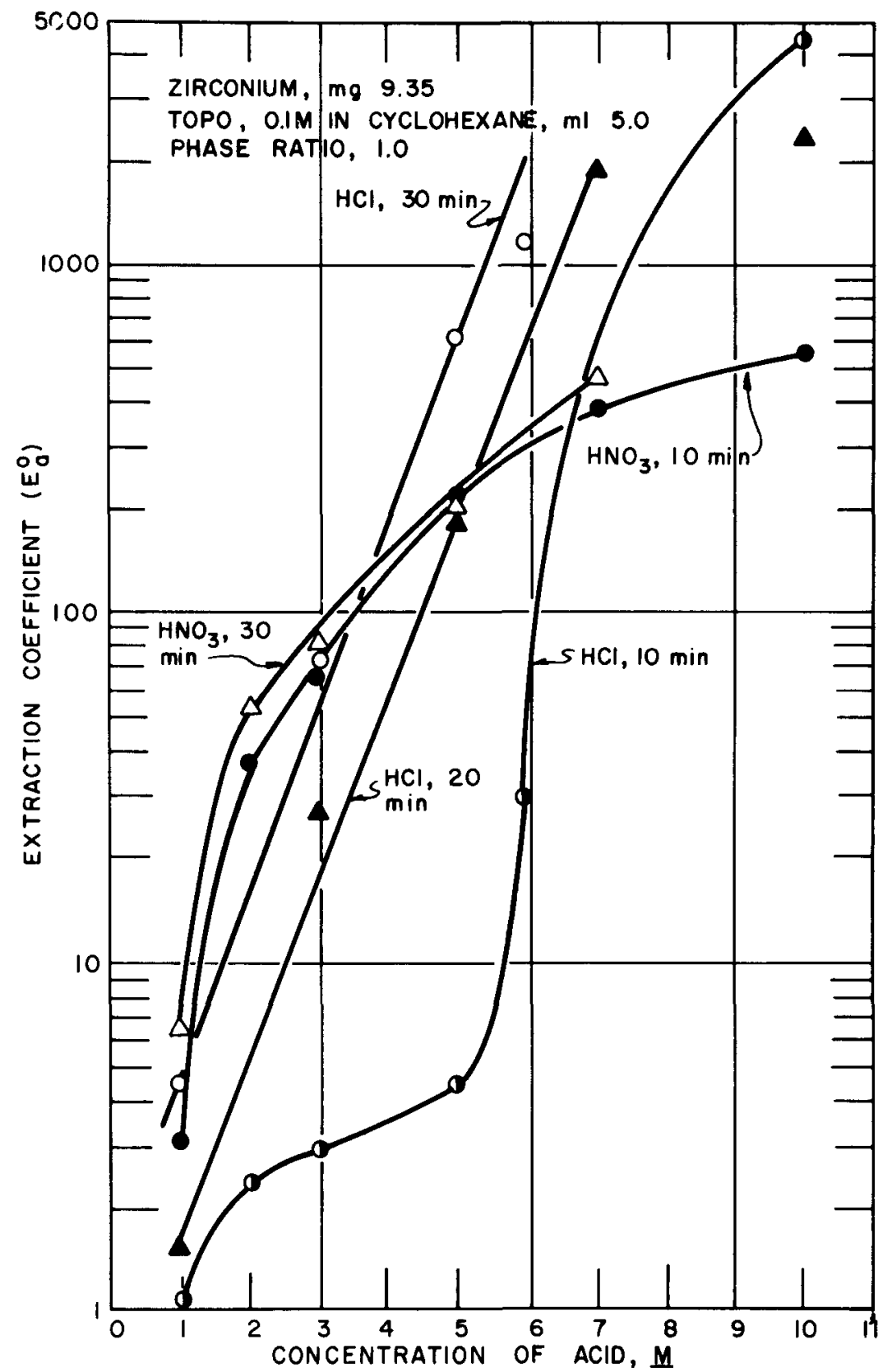

FIGURE 8. EFFECT OF ACID CONCENTRATION AND EXTRACTION TIME ON THE EXTRACTION OF ZIRCONIUM WITH 0.1 M TRI-N-OCTYLPHOSPHTNE OXIDE 


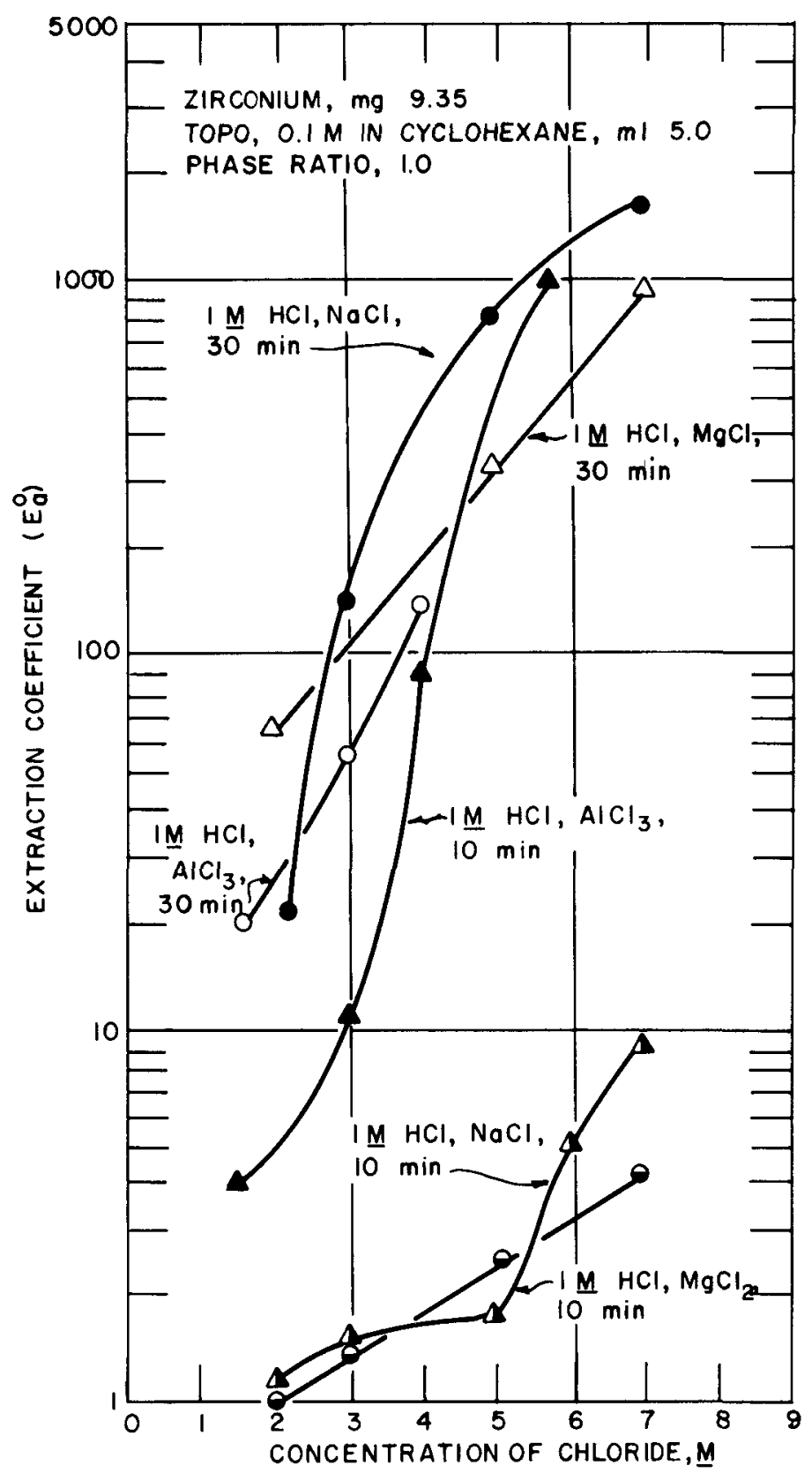

FIGURF 9. EXTRACTICN OF ZIRCONIUM BY $0.1 \mathrm{M}$ TRI-N-OCTYIPHOSPHINE OXIDE AS A FUNCTION OF THE CONCENTRATION OF CHLORIDE SALTS OF UNI-, DI-, AND TRI-VAIENT METALS 


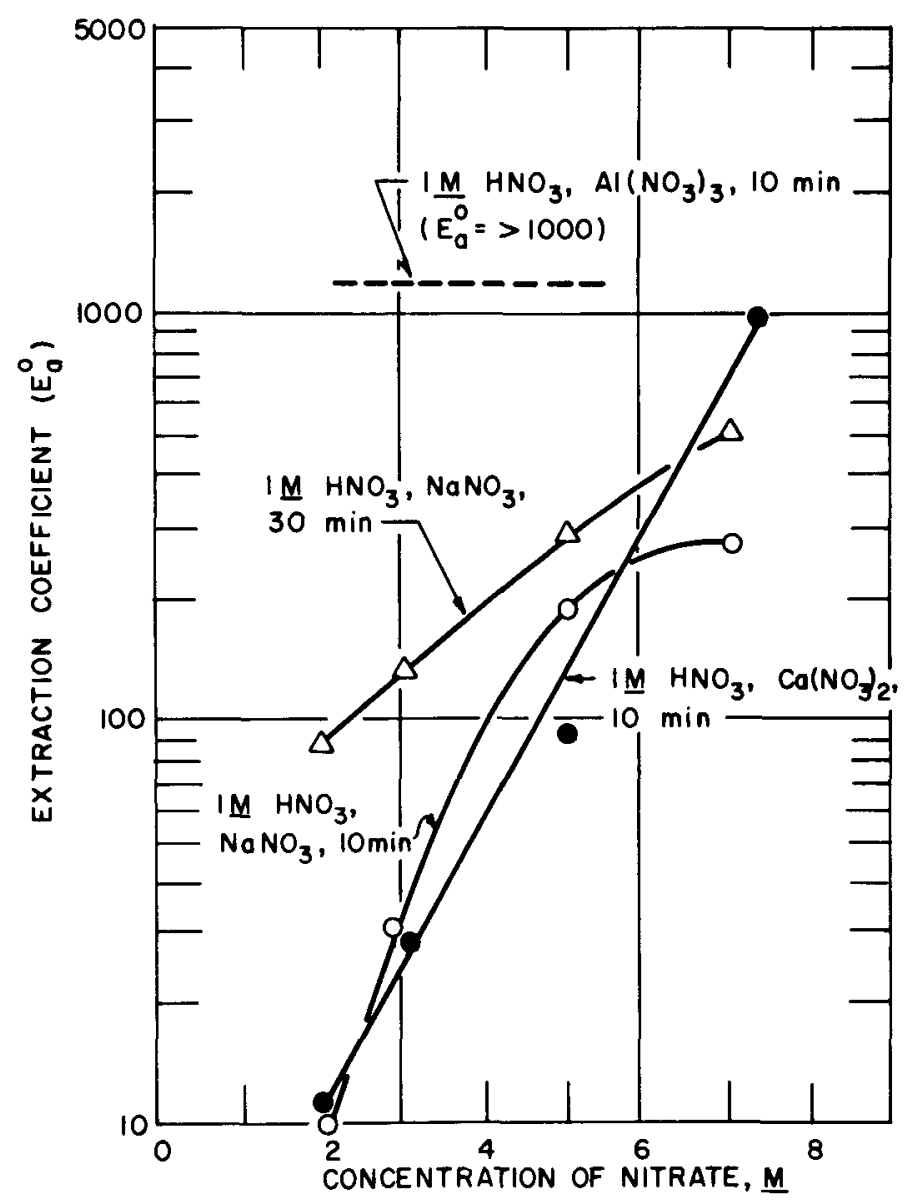

FLSTHLS 10. DXPRACLION OF ZIRCONLIJM EV O.J M TRI-N-OC PYLPACSEFINE OXIDE AS A FUNCTIOV OF THE CORCEVTRATION OF NITRATT SALTS OF UNI-, II-, AID TRI-VALENT MLTALS. $\mathrm{Zr}-9.35 \mathrm{mg}$; rOPO - $0.1 \mathrm{M}$ in cyclohexane, $5 \mathrm{ml}$; and Phase ratio - 1 .

the degree of extraction increases with acidity. Perchlorate media are not suitable for analytical separations of zirconium because of the relatively Low solubility of the zirconium perchlorate adduct in cyclohexane. Threephase systems are observed when saturation of TOPO is approached either with acid or zirconium.

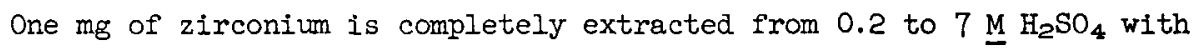
$5 \mathrm{ml}$ of $0.1 \mathrm{M}$ TOPO in cyclohexane. The adduct hydrolyzes slowly in systems that contain less than $3 \mathrm{M} \mathrm{H}_{2} \mathrm{SO}_{4}$ and precipitates at the interface as a white solid. As much as $10 \mathrm{mg}$ of zirconfum is extracted to an extent that exceeds 98 per cent from 3 to $5 \mathrm{M} \mathrm{H}_{2} \mathrm{SO}_{4}$ with 1 millimole of TOPO. The fact 
that the extraction of zirconium from sulfate solutions is impaired by the addition of neutral sulfate salts (Figure Il) is indicative of the formation

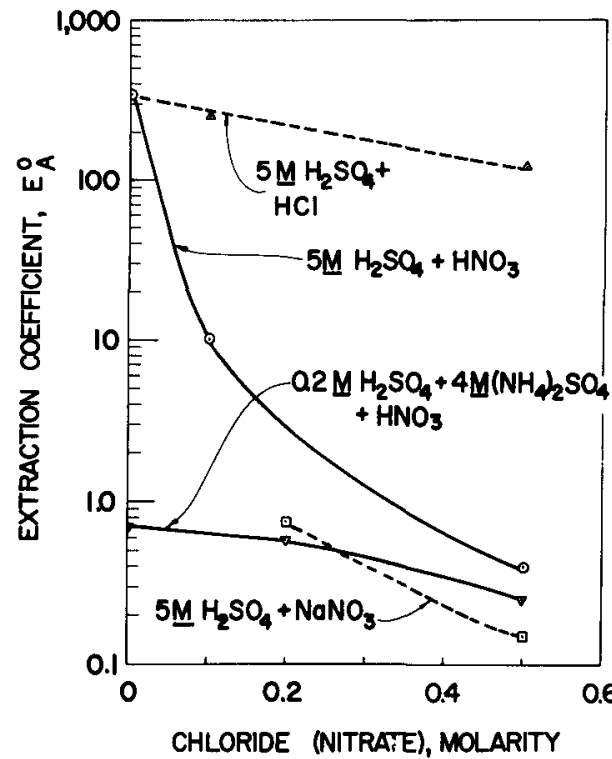

FIGURE 11. EFFECT OF CHLORIDE AND NITRA TE ON THE EXTRACTION OF ZIRCONIUM FROM SULFATE SOLUTIONS WITH TRI-N-OCTYLPHOSPHINE OXIDE. Zirconium - $1 \mathrm{mg}$; TOPO - $0.1 \mathrm{M}$ in cyclohexane, $5 \mathrm{ml}$; Phase ratio $=1$; and Extraction time - 30 minutes.

of less extractable complexes of zirconium sulfate in the aqueous phase. Zirconium extraction is likewise decreased when nitrate is added to a sulfate solution since nitric acid is extracted as well as the zirconium sulfate species. Chloride has only a slightly detrimental effect.

Zirconium is extracted from nitrate and chloride solutions as $\mathrm{Zr}\left(\mathrm{NO}_{3}\right)_{4} \cdot 2$ (TOPO) and $\mathrm{ZrCl}_{4} \cdot 2$ (TOPO) along with varying amounts of the inorganic acid. The phosphine oxide is saturated with zirconium only when an excess of zirconium is present in the aqueous phase. The amount of zirconium extracted is directly dependent on the amount of TOPO in the organic phase. The degrees to which various quantities of zirconium are extracted with 0.5 millimole of TOPO are shown in Tigure 12.

Quantitative separations can also be achieved from chloride solutions, but not from nitric acid solutions, with $0.01 \mathrm{M}$ solutions of TOPO in cyclohexane (Figure 13).

Zirconium is not extracted with TOPO from hydrofluoric acid solutions. Consequently, I M HF solutions have been used effectively to strip zirconium 


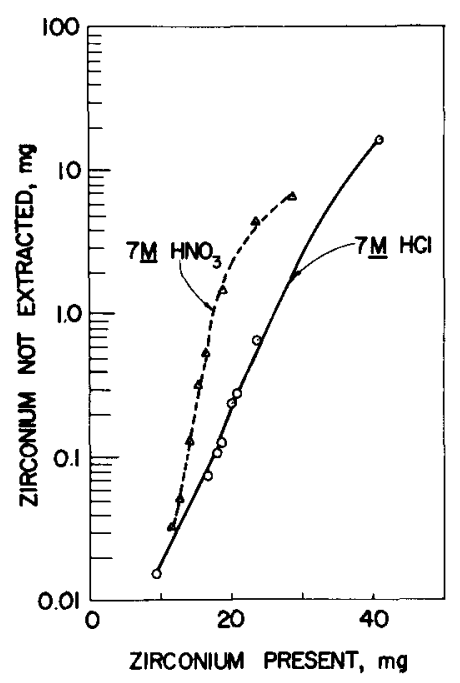

FIGURE 12. EXTRACTION OF ZIRCONIUM WTTH $0.1 \mathrm{M}$ TRI-N-OCTYLPHOSPHINE OXIDE. TOPO - $0.1 \mathrm{M}$ in cyclohexane, $5 \mathrm{ml}$;

Phase ratio - 1 ; and Extraction time 10 minutes.

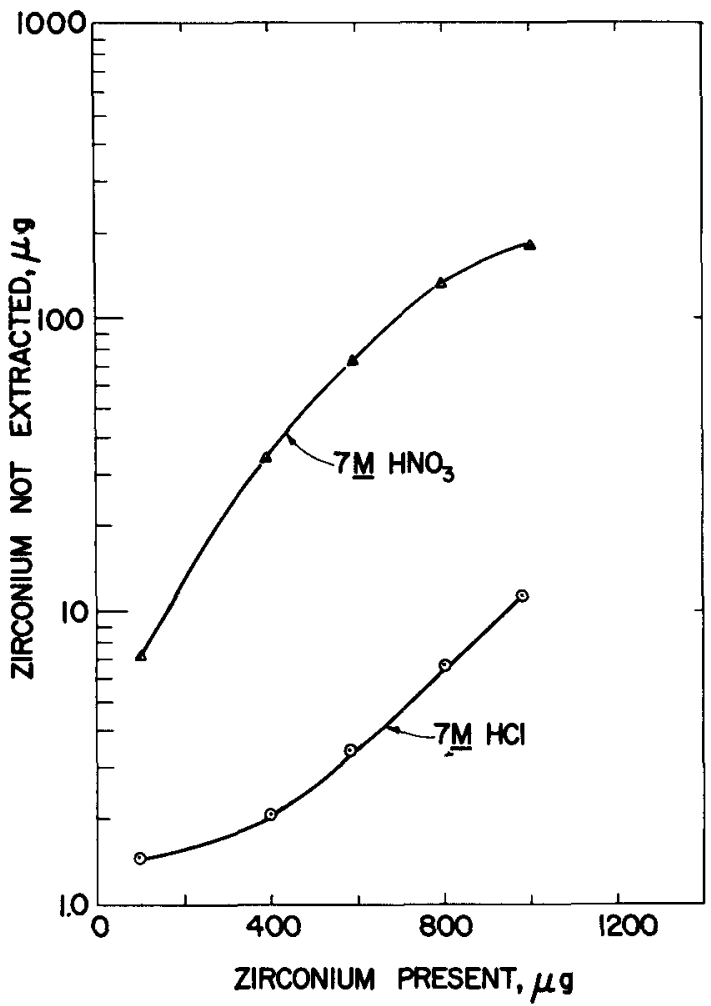

FIGURE 13. EXTRACTION OF ZIRCONIUM WITH $0.01 M$ TRI-N-OCTYLPHOSPHINE OXIDE. TOPO - O.I $M$ in cyclohexane, $5 \mathrm{ml}$; Phase ratio - 1; and Extraction time 20 minutes.

from cyclohexane solutions of TOPO. Partial extraction of zirconium can be achieved from fluoride solutions by complexing the fluoride with aluminum nitrate. Quantitative extraction has not been obtained, however, when the mole ratio of aluminum to fluoride is as high as 10.

Likewise, the extraction of zirconium is retarded by the presence of hydroxy-organic acids and ethylenediaminetetraacetate. The detrimental effect of such acids as tartaric can be overcome to a large extent when the aqueous phase is $7 \underline{\mathrm{M}}$ in $\mathrm{HCl}$ or $\mathrm{HNO}_{3}$ as shown in Table $\mathrm{I}$.

Variation of the aqueous to organic phase ratio from 1 to 20 has a slight effect on the extraction of $10 \mathrm{mg}$ of zirconium (Figure 14). The extraction of larger amounts of zirconium, especially from nitrate solutions, is impaired when the volume of the tqueous phase is increased; 
FFFECT OF TARTRATE ON THE EXTRACTION OF ZIRCONIUM FROM CHLORIDE AND NITRATE SOLUTIONS

\begin{tabular}{|c|c|c|c|c|c|}
\hline \multirow{3}{*}{ Acid } & \multicolumn{3}{|c|}{$\begin{array}{l}\mathrm{HCl}\left(\mathrm{HNO}_{3}\right), \mathrm{M} \\
\text { TOPO, } 0.1 \mathrm{M} \text { in cyclohexane, ml } \\
\text { Equilibration time, minutes } \\
\text { Phase ratio }\end{array}$} & $\begin{array}{r}7 \\
5 \\
10 \\
1\end{array}$ & \multirow{3}{*}{$\mathrm{E}_{\mathrm{a}}^{\mathrm{O}}$} \\
\hline & \multirow{2}{*}{$\begin{array}{l}\text { Tartrate, } \\
\text { Molarity }\end{array}$} & \multicolumn{3}{|c|}{ Zirconium, mg } & \\
\hline & & Present & Organic & Aqueous & \\
\hline \multirow[t]{4}{*}{$\mathrm{HCl}$} & 0.10 & 23.3 & 21.7 & 1.61 & 13.5 \\
\hline & .25 & & 21.6 & 1.68 & 12.9 \\
\hline & .50 & & 21.1 & 2.22 & 9.52 \\
\hline & 1.0 & & 20.8 & 2.52 & 8.26 \\
\hline \multirow[t]{4}{*}{$\mathrm{HNO}_{3}$} & 0.10 & 15.1 & 14.5 & 0.613 & 23.7 \\
\hline & .25 & & 14.3 & .804 & 17.8 \\
\hline & .50 & & 14.2 & .861 & 16.5 \\
\hline & 1.0 & & 14.0 & 1.07 & 13.1 \\
\hline
\end{tabular}

however, complete extraction is readily achieved by two extractions when the phase ratio, $V_{a} / V_{O}$, is less than 10 .

The applicability of TOPO to the extraction of radio-zirconium has been investigated to a small extent. The extraction characteristics of zirconium-95, in the presence of 20 micrograms of stable zirconium carrier, have been determined in hydrochloric, nitric, and sulfuric acid systems. Zirconium-95 in an oxalate solution was obtained from the Oak Ridge National Laboratory and separated from niobium-95 by extraction with thenoyl trifluoroacetone (ITA) according to the procedure described by Moore. (9) Portions of the purified tracer were convezted to chloride, nitrate, and sulfate salts and dissolved in $1 \mathrm{M}$ solutions of the corresponding acid to yield solutions that emitted $10^{5}$ gamma photons per minute per ml. One-ml allquots of these solutions were used in each extraction test within eight hours after purification. The effect of various concentrations of hydrochloric, nitric, and sulfuric acids on the extraction of tracer and carrier are presented in Figure 15. These data show that complete extraction is achieved from $>5 \underline{\mathrm{M} \mathrm{HCl}}, 0.5$ to $10 \underline{\mathrm{M}} \mathrm{HNO}_{3}$ and 0.2 to $7 \underline{\mathrm{M} \mathrm{H}} \mathrm{H}_{4}$. 


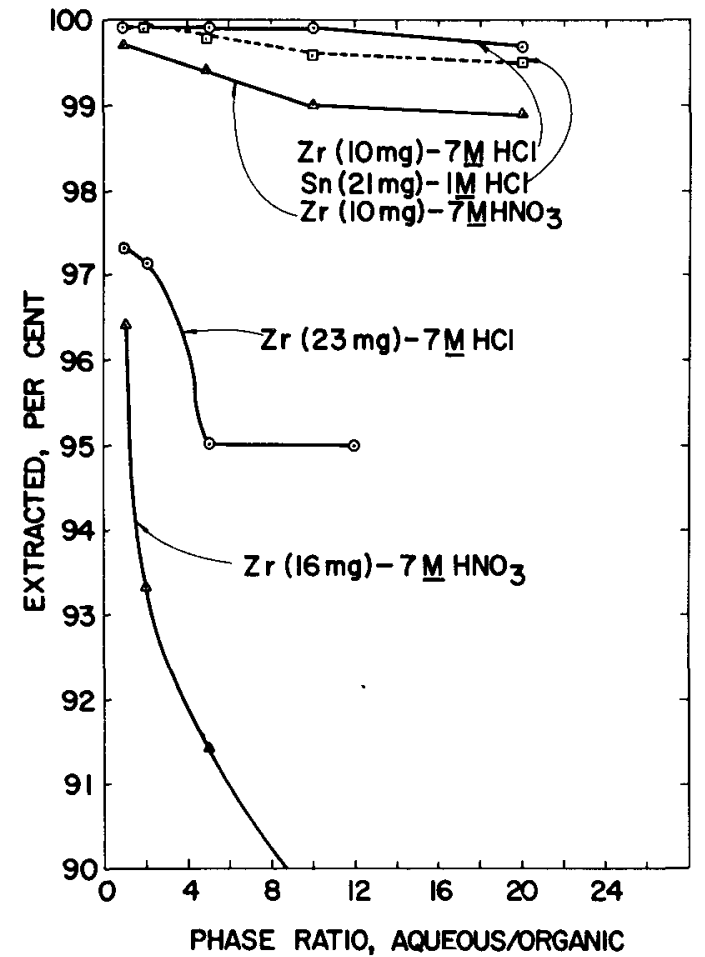

FIGURE 14. EXTRACTION OF TIN(IV) AND ZIRCONIUM WITH TRI-N-OCTYLPHOSPHINE OXIDE AS A FUNCTION OF EXTRACTION TIME. TOPO, $0.1 \mathrm{M}$ in cyclohexane, $5 \mathrm{ml}$; and Extraction time - 10 minutes.

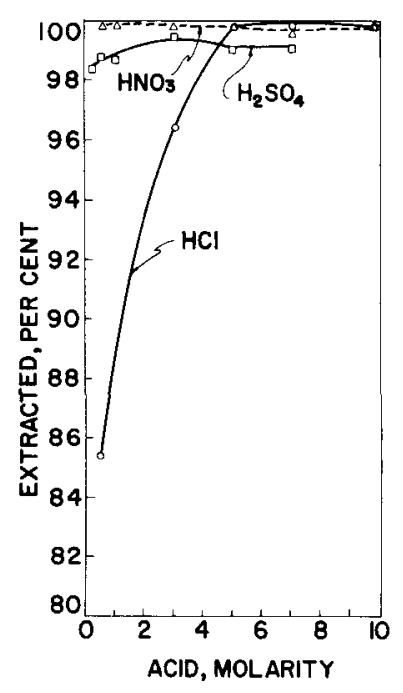

FIGURE 15. EXTRACTION OF ZIRCONIUM-95 TRACER. ZIrConium Carrier - $20 \mathrm{\mu g}$; TOPO - $0.1 \mathrm{M}$ in cyclohexane, $5 \mathrm{ml}$; Phase ratio 1 ; and Extraction time - 30 minutes.

Hafnium. On the basis of qualitative data, the extraction characteristics of hafnium are considered to be very similar to those of zirconium in that hafnium is extractable from 1 to $7 \mathrm{M} \mathrm{HCl}, \mathrm{H}_{2} \mathrm{SO}_{4}$, $\mathrm{HNO}_{3}$, and $\mathrm{HClO}_{4}$.

Silicon. No extraction studies have been performed with watersoluble compounds of silicon. Precipitation occurs when an acid silicate solution is equilibrated with cyclohexane solutions of TOPO.

Germanium has been found, by qualitative tests, to be more extractable from 7 M acid solutions than from $I$ M acid media.

Tin exhibits the greatest extractability with TOPO of any element investigated. Extraction occurs, however, only from solutions that contain chloride. The extracted species is $\mathrm{SnCl}_{4} \cdot 2$ (TOPO), regardess of the oxidation state of tin in the original aqueous solution. Identical extrac- 
tion characteristics are obtained with solutions prepared with $\mathrm{SnCl} \mathrm{H}_{4} \cdot 5 \mathrm{H}_{2} \mathrm{O}$, $\mathrm{SnCl}_{2} \cdot 2 \mathrm{H}_{2} \mathrm{O}$, or from the dissolution of the metal with hyirochloric acid in the presence or absence of oxygen.

Tin is extracted most readily from relatively dilute acid chloride solutions (Figure 16). The degree of extraction is primarily dependent on

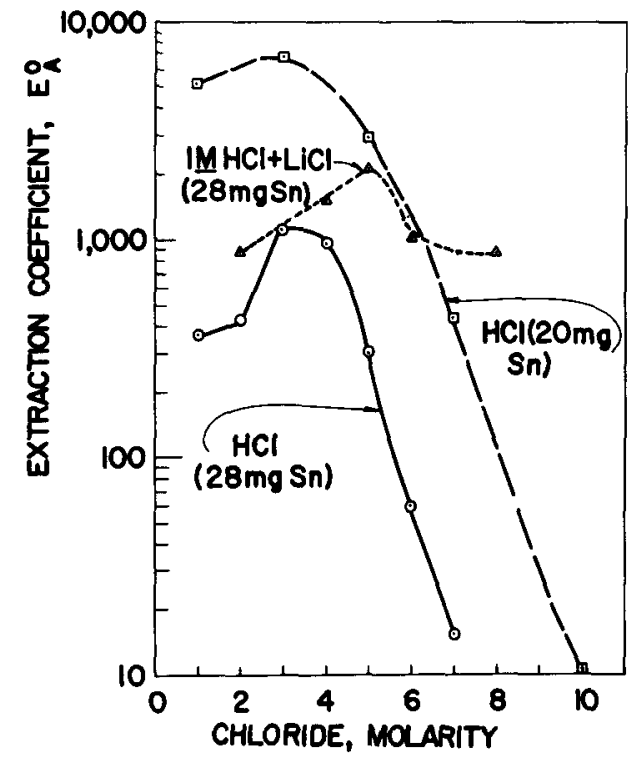

FIGIJRE 16. EXTRACTION OF TIN(IV) VITH TRT-N-OCTYLPHOSPHINE OXIDE AS A FUNJCTION OF CHLORIDE CONCENTRATION. TOPO - $0.1 \mathrm{~W}$ in cyclohexane, $5 \mathrm{ml}$; Phase ratio - 1 : Extraction time - 10 minutes.

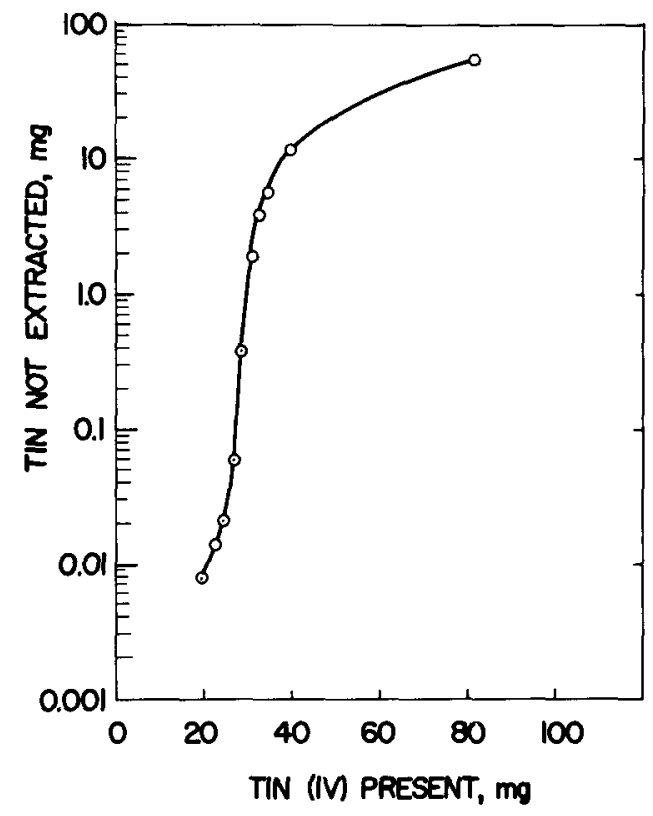

FIGURE 17. FXXTRACTION OF TIN(IV) FROM CHLORIDE SOLUTIONS AS A FUNCTION OF TIN CONCENTRATION. TOPO - $0.1 \mathrm{M}$ in cyclohexane, $5 \mathrm{ml}$; HC1 - 1 M; Phase ratio -1 ; and Extraction time - 10 minutes.

the concentration of chloride, although the aqueous phase must be at least $I \underline{M}$ in hydrogen ion to prevent hydrolysis of tin. Bxtraction from $1 \underline{\mathrm{M}} \mathrm{HCl}$ is 99 per cent complete after one minute and 99.7 per cent complete after three minutes. Variation of the aqueous/organic phase ratio from 1 to 20 has no effect on the extraction when the phases are mixed for 10 minutes (Figure 14).

The degree to which various amounts of tin are extracted by 0.5 mill1mole of TOPO are shown in Figure 17. Approximately 90 per cent (27. mg) of the stoichiometric amount of $\operatorname{tin}(29.8 \mathrm{mg})$ can be extracted completely 
in a single, 10-minute extraction, while 98 per cent of the stolchiometric amount is extracted from a solution that contains only $30.8 \mathrm{mg}$ of tin.

In the absence of chloride, tin is not extracted from nitric or sulfuric acid solutions. The addition of sulfuric acid to $1 \mathrm{M}$ HCI solutions of tin enhances the extraction slightly by reducing the amount of acid that is co-extracted (Figure 18). The extraction of $t$ in is continuously decreased when perchloric or nitric acid is added to an aqueous solution that is 1 in $\mathrm{HCl}$.

Lead, as the nitrate, is not extracted from either perchloric or nitric acid medie.

\section{Extraction of Elements in Periodic Group V.}

Vanadium. Quadrivalent vanadium is not extracted from acid solutions with cyclohexane solutions of ropo.

Pentavalent vanadium is partially extracted from 1 to $7 \mathrm{M} \mathrm{HCl}$ but is not extracted from $I \underline{M}$ nitric or sulfuric acid solutions (Figure 19).

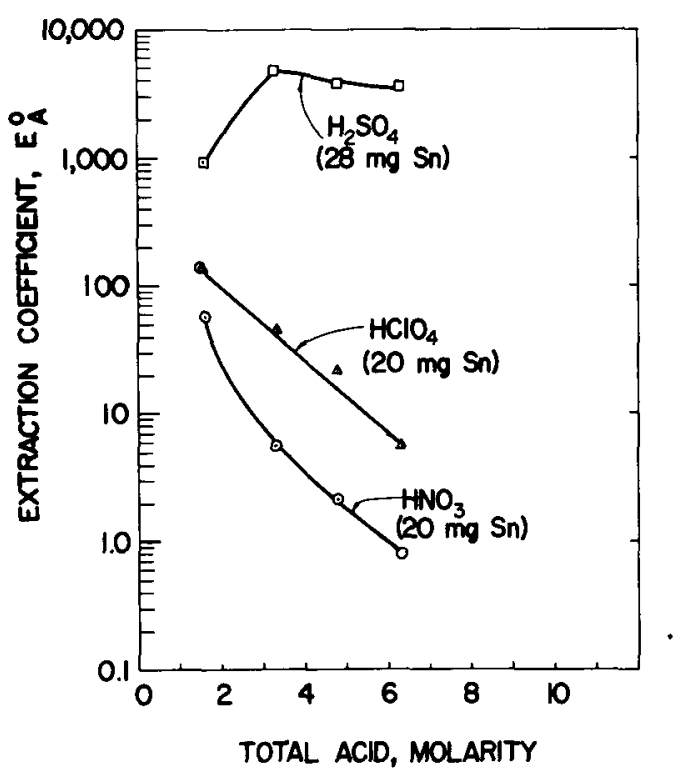

FIGURE 18. SFTECT OF SULFATE, $Y$-RCILORATA HID 'ITRATE ON TTE EXTRACTTON UF TIN(IT) FRO: CNLOIIDE SOLUTIONS WTH TRI-N-LCI T'H.SFTINE OXIDE. TOPO - 0.7 li in CyC7.0hoxane, $5 \mathrm{ml}$; $\mathrm{HCl}$ - I. $\mathrm{l}$; thase ratio - I; Txtractjon tine - 10 rinutes.

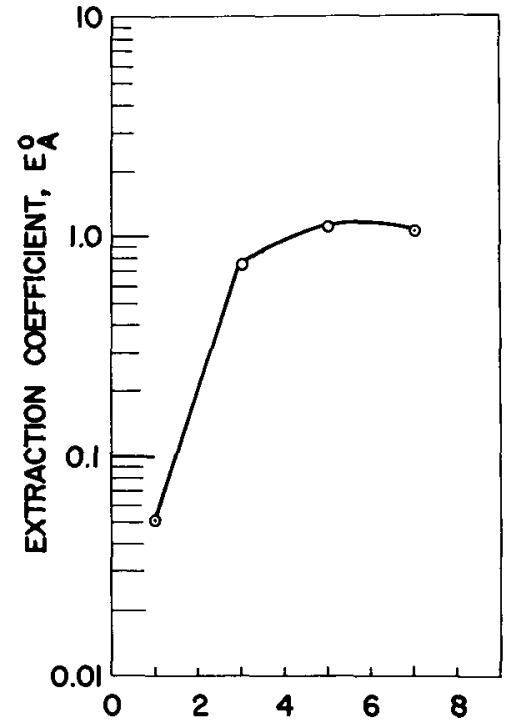

HYDROCHLORIC ACID, MOLARITY

FIGURE 19. EXTRACTION OF VANADTUR(V) WITH TRI-N-OCTYLPHOSPHINE OXIDE AS A FUNCTION OF HYDROCHLORIC ACID CONCENTRATION. Vanadium - $6.2 \mathrm{mg}$; TOPO $0.1 \mathrm{M}$ in cyclohexane, $5 \mathrm{ml}$; Phase ratio - 1 ; and Extraction time - 10 minutes. 
Extraction has been achieved, however, from $0.5 \mathrm{M}$ sulfate solutions of pH 1 to 2.5 when nitrate salts are added. The data presented in Table II was obtained by Blake, Brown, and Coleman while using kerosene solutions of Topo. (1)

TABLE II

EFFECT OF NITRATE AND PH ON EXTRACTION OF VANADIUM(V)

Vanadium - $0.004 \mathrm{M}$

TOPO - $0.2 \mathrm{M}$ in kerosene

Sulfate - $0.5 \mathrm{M}$

Phase ratio - I

\begin{tabular}{|c|c|c|c|c|}
\hline \multirow{3}{*}{$\begin{array}{l}\text { Nitrate, } \\
\text { M }\end{array}$} & \multicolumn{4}{|c|}{ Extraction Coefficient } \\
\hline & & In & $\mathrm{pH}$ & \\
\hline & 1.0 & 1.5 & 2.0 & 2.5 \\
\hline 0 & 0.1 & 0.1 & 0.1 & 0.2 \\
\hline 0.05 & 0.9 & 0.6 & 0.8 & 0.5 \\
\hline 0.2 & 2.0 & 2.0 & 2.0 & 1.1 \\
\hline 0.3 & 2.5 & 4.7 & 3.2 & 1.1 \\
\hline 0.5 & 5.0 & 6.8 & 3.2 & 0.9 \\
\hline 1.0 & 4.3 & 10 & 10 & 1.1 \\
\hline
\end{tabular}

Niobium. (7) Niobium(V) is extracted with cyclohexane solutions of TOPO only from those hydrochloric acid solutions in which a sufficient concentration of some complexing agent, such as oxalic, tartaric, citric, or lactic acid, is present. Niobium-95 tracer is extracted to a degree greater than 99 per cent from solutions that are $4 \mathrm{M}$ in $\mathrm{HCl}$ and which contain $0.33 \underline{M}$ tartaric acid or $0.2 \underline{M}$ lactic acid. Extraction does not occur in the presence of nitric acid. In sulfuric acid systems, hydrolysis occurs too rapidly to permit useful extractions.

Tantalum. (7) The extraction of tantalum is similar to, but generally less than that of niobium. In $6 \mathrm{M} \mathrm{HCl}-0.2 \mathrm{M}$ lactic acid, approximately 60 per cent of $5.5 \mathrm{mg}$ of tantalum, plus tantalum-181 tracer, is extracted.

Arsenic. Trivalent arsenic is partially extracted from acld chloride solutions (F1gure 20) but not from nitric or sulfuric acid media.

Pentavalent arsenic is not extracted from acidic solutions with cyclohexane solutions of TOPO. 


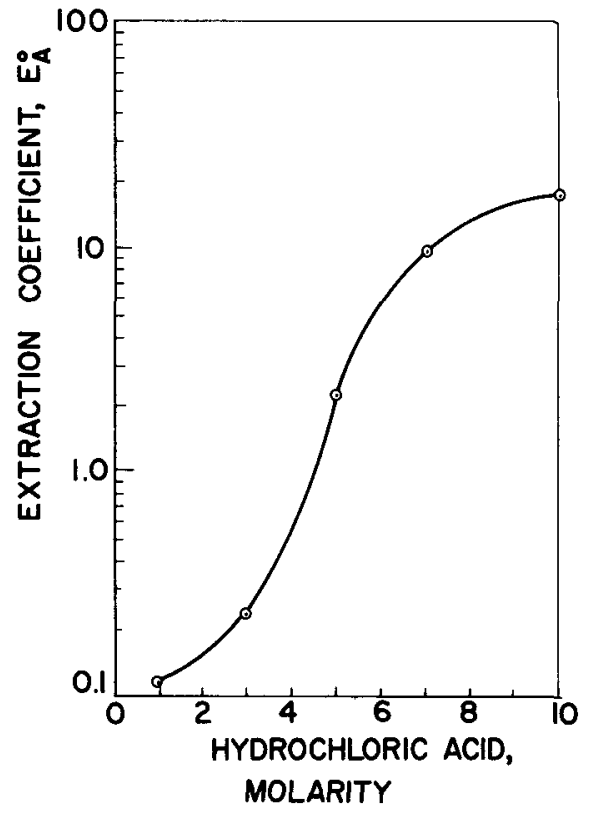

FIGURE 20. EXTRACTION OF ARSENIC(III) WITH TRI-N-OCTYLPHOSPHINE OXIDE AS A FUNCTION OF HYDROCHLORIC ACID CONCENTRATION. Arsenic(III) - $1.0 \mathrm{mg}$; TOPO $0.1 \mathrm{M}$ in cyclohexane, $5 \mathrm{ml}$; Phase ratio1 ; añd Extraction time - 10 minutes.

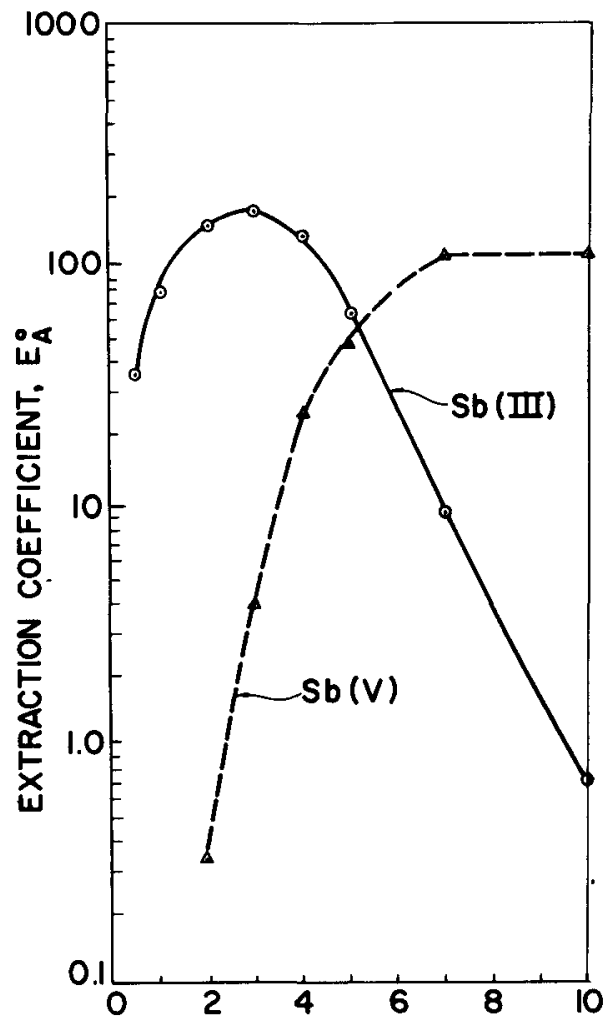

HYDROCHLORIC ACID, MOLARITY

FIGURE 21. EXTRACTION OF ANTIMONY WITH TRI-N-OCTYLPHOSPHINE OXIDE AS A FUNCTION OF HYDROCHLORIC ACID CONCENTRATION. Antimony(III) $10 \mathrm{mg}$; Antimony(V) - $9 \mathrm{mg}$; TOPO $0.1 \mathrm{M}$ in cyclohexane, $5 \mathrm{ml}$; Phase ratio - 1; and Extraction time 10 minutes.

Antimony. The extraction characteristics of trivalent antimony parallel those of tin in that extraction occurs only from chloride media. The degree of extraction is dependent on the concentration of hydrochloric acid; being at a maximum in $3 \underline{M} \mathrm{HCl}$ systems (Figure 2l). Even though antimony is partially hydrolyzed and precipitated in 0.5-1.0 $\mathrm{M} \mathrm{HCl}$ solutions, the solid is redissolved during extraction and a large percentage of the antimony extracted from these media. Application of dilute hydrochloric solutions is readily carried out, however, by adding neutral chloride salts or sulfuric acid to enhance the extraction of antimony(III) 


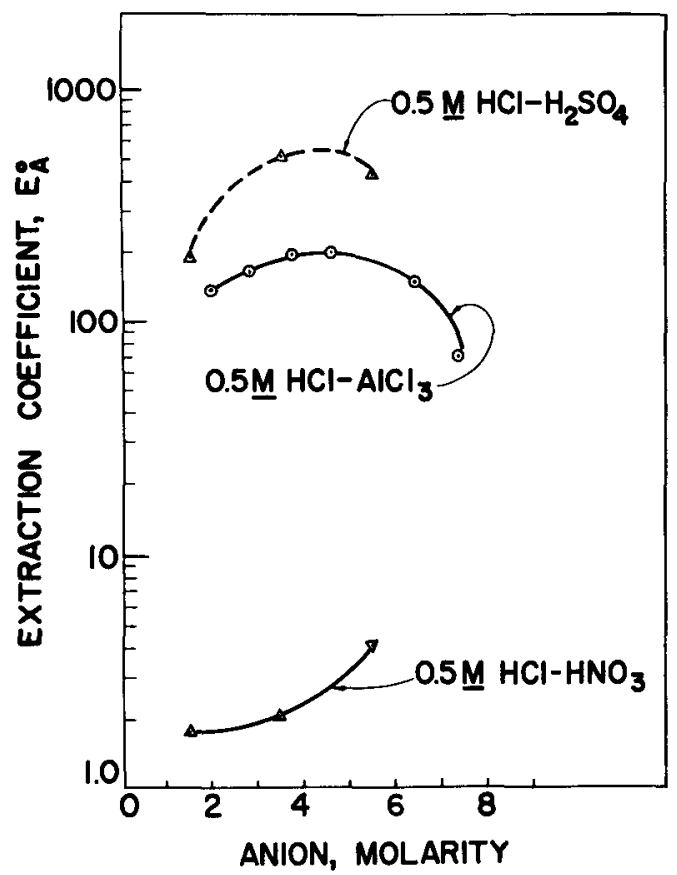

FIGURE 22。 EXTRACTION OF ANTIMONY (III) FROM CHLORIDE SOLUTIONS WITH TRI-N-OCTYLPHOSPHINE OXIDE AS A FUNCTION OF CHLORIDE, NITRATE, AND SULFATE CONCENTRATION. Antimony $10 \mathrm{mg}$; HCl $-0.5 \mathrm{M}$; TOPO - $0.1 \mathrm{M}$ In cyclohexane, $5 \mathrm{ml}$; Phase ratio 1 ; and Extraction time - 10 minutes.

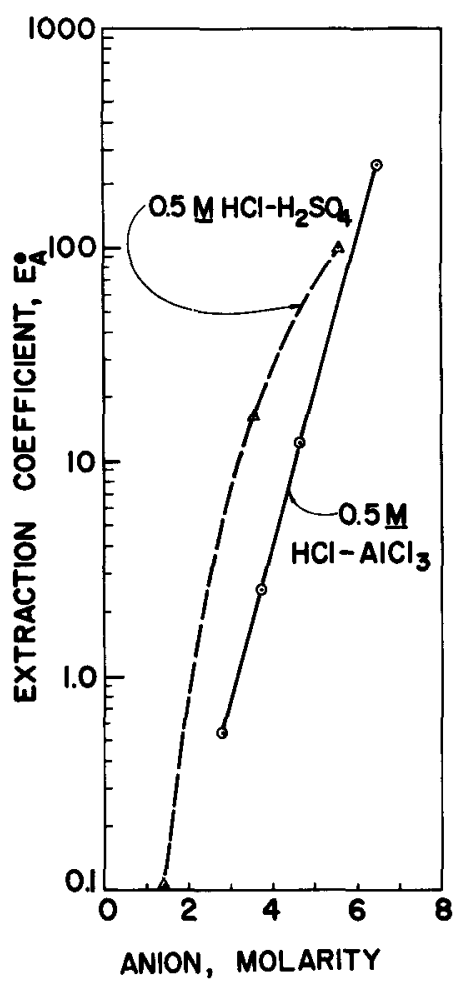

FIGURE 23. EFFECT OF CHIORIDE AND SULFATE ON THE EXTRACTION OF ANTIMONY (V) FROM CHLORIDE SOLUTIONS WITH TRIN-OCTYLPHOSPHINE OXIDE. Antimony $9 \mathrm{mg}$; HCl - $0.5 \mathrm{M}$; TOPO - $0.1 \mathrm{M}$ in cyclohexane, $5 \mathrm{mI}$; Phase ratio- -1 ; and Extraction time - 10 minutes.

in excess of 99 per cent (Figure 22). Nitrate depresses the extraction of antimony(III) from chloride solutions.

The extraction of antimony(V) is enhanced as the concentration of hydrochloric acid is increased (Figure 2l). Antimony(V) precipitates from 0.5 to $1.0 \mathrm{M} \mathrm{HCl}$ solutions and the solid does not redissolve during equilibration of the phases. As with antimony(III), the degree of extraction of antimony $(V)$ is primarily a function of the chloride concentration of the aqueous phase and can be enhanced by the addition of chloride salts to a very dilute acid solution (Figure 23). Likewise, the extraction of antimony(V) is enhanced markedly by the addition of sulfuric acld to a dilute hydrochloric acid solution of antimony. This enhancement is due primarily to the "salting-out" effect of the sulfuric acld and the decrease 
in co-extraction of mineral acid when sulfurlc is substituted for hydro-

chloric acid in the aqueous phase.

Bismuth. Bismuth(III) is extracted fram chloride, sulfate, and nitrate solutions with TOPO. The extraction characteristics of this element differ from most of the other extractable species in that maximum extraction is achieved in the most dilute acid permissable without hydrolysis and precipitation of bismuth (Figure 24). In chloride systems the extracted species

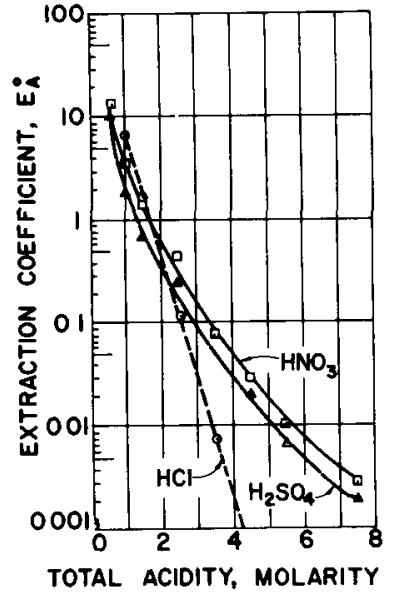

FIGURE 24. EXTRACTION OF BISMUTH FROU ACIDIC SOLUTIONS BY TRI-NOCTYLPHOSPHINE OXIDE AS A FUNCTION OF TYPE AND CONCENTRATION OF ACID. Bismuth - $20 \mathrm{mg} ; \mathrm{HNO}_{3}-0.5 \mathrm{~K}$; TOPO - $0.1 \mathrm{M}$ in cyclohexane, $-5 \mathrm{ml}$; Phase ratio- 1 ; and Extraction time - 10 minutes.

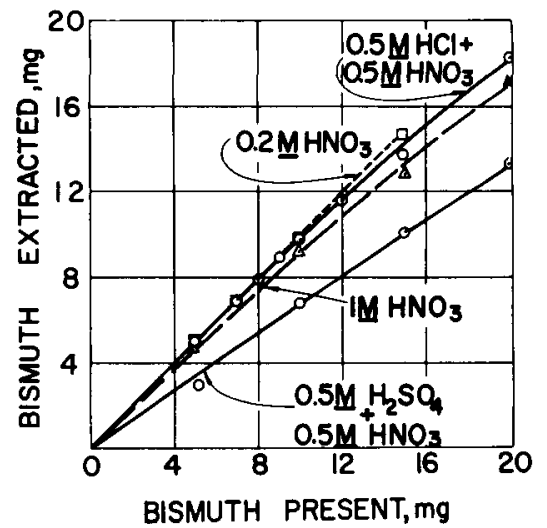

FIGURE 25. BISMUTH ISOTHERMS IN DILUTE ACID-TRI-N-OCTYLPHOSPHINE OXIDE SYSTEMS. TOPO - $0.1 \mathrm{M}$ in cyclohexane, 5 ml; Phase ratio - 1; and Extraction time - 10 minutes.

is $\mathrm{BiCl}_{3} \cdot 2$ (TOPO). The impairment in extraction that results from increased acidity is probably caused by the formation of less extractable anionic complexes of bismuth chloride in the aqueous phase. Essentially, no extrac-

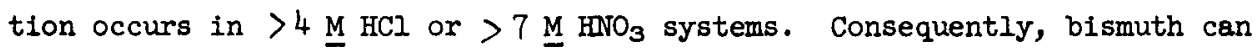
be removed quantitatively from a cyclohexane solution of TOPO by back-

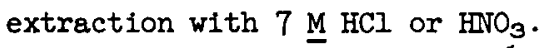

Complete extraction of bismuth can be approximated by decreasing the concentration of mineral acids to below $1 \underline{M}$ (Figure 25). As much as 5, 10, and $15 \mathrm{mg}$ of bismuth can be extracted by 0.5 millimole of TOPO to an extent greater than 95 per cent from solutions that are $1 \underline{M}$ in $\mathrm{HNO}_{3}, 0.5 \underline{\mathrm{M}}$ in $\mathrm{HCl}$ 
$+0.5 \mathrm{M}$ in $\mathrm{HNO}_{3}$, and $0.2 \mathrm{M}$ in $\mathrm{HNO}_{3}$, respectively. The marked dependence of extraction necessitates close control over the acid concentration of the aqueous phase.

Extraction of Elements in Periodic Group VI.

Chromi-um. (16) Chromium(III) is not extracted from acidic solutions with TOPO.

Chromium(VI) is readily extracted from hydrochloric acia solutions and to lesser extents from sulfuric, nitric, perchloric, and phosphoric acids (Figure 26). Chromium ditfers from other elements extracted by TOPO in that it can be extracted as an anionic species with the approximate composition of $\mathrm{H}_{2} \mathrm{Cr}_{2} \mathrm{O}_{7} \cdot 2$ (TOPO), and forms an adduct with TOPO in which the phosphoryl oxygen is coordinated with a hydrogen atom. Consequently, maximum extraction of chromium is achieved in those systems where (1) $\mathrm{H}_{2} \mathrm{Cr}_{2} \mathrm{O}_{7}$ is formed, and (2) the extractability of the mineral acid is low. Otherwise, the extractable species of chromium is essentially uninfluenced by the nature of anions present in the aqueous phese, and chromium can be extracted from any mineral acid. For the same reason, no enhancement in extraction is realized when neutral salts are added to the aqueous phase (Figure 27). Contrariwise, the degree of extraction is decreased due to a shift in the equilibria between acidic and neutral chromate entities to favor the neutral species.

In concentrated acid systems $\left(>10 \underline{\mathrm{M}}\right.$ ) the red-brown $\mathrm{H}_{2} \mathrm{Cr}_{2} \mathrm{O}_{7}$-TOPO adduct rapidly changes to a green color due to reduction of chromium(VI) by the organic environment. As indicated by the stoichiometry of the postulated extracted species, the amount of chromium extracted is directly proportional to the amount of TOPO present. In systems that contain 0.5 millimole of TOPO, as much as $9 \mathrm{mg}$ of chromium is 99 per cent extracted, in a single, 10-minute equilibration, from I $\mathrm{M} \mathrm{HCl}$ (Figure 28). Complete extraction is not achieved from other acids by a single equilibration. Complete saturation of 0.5 millimole of TOPO with chromium (26 mg) is achieved from $\mathrm{I} \mathrm{M} \mathrm{H}_{2} \mathrm{SO}_{4}$ when $>35 \mathrm{mg}$ of chromium(VI) is present initially. 


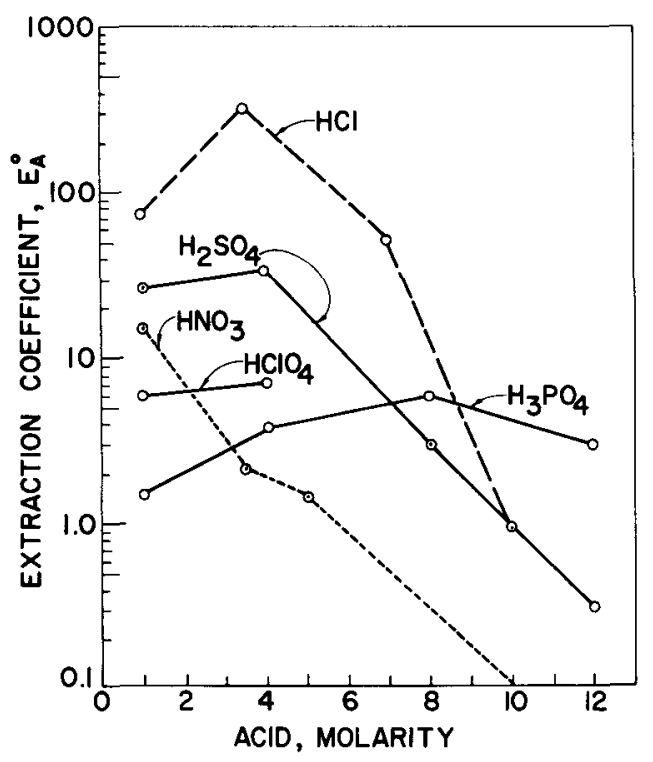

FIGURE 26. EXTRACTION OF CHROMIOM (VI) WITH TRI-N-OCTYLPHOSPHINE OXIDE EFFECT OF CONCENTRATION OF ACID. Chromium - $10.3 \mathrm{mg}$; TOPO $0.1 \mathrm{M}$ in cyclohexane, $5 \mathrm{ml}$; Phase rati $\overrightarrow{0}-1$; and Extraction time 10 minutes.

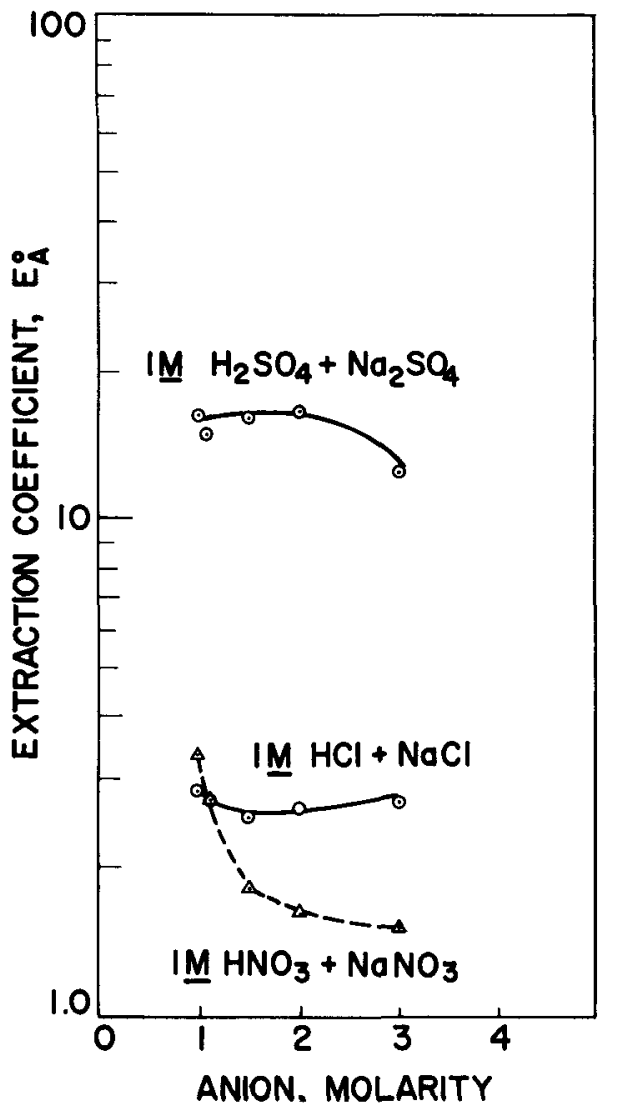

FIGURE 27. ETECT OF CIILORIDE, MITRATE, AND SULFATE ON THE EXTRACTION OF CTRONITM(VI) IITI TRI-N-OCTYIPAOSPHITT OXIDE. Chrorn um 2]. $\mathrm{rg}$; TOPO - $0.7 \mathrm{~V}$ in cyclohexane, $5 \mathrm{~mJ}$; Phase ratio - 1 ; and Extraction time - 10 minutes.

Saturation is not achieved from $1 \mathrm{M} \mathrm{HNO}_{3}$ systems until $200 \mathrm{mg}$ of chromium is present and is not attained in $1 \mathrm{M} \mathrm{HCl}$ media even at this concentration level. Extraction equilibrium is attained rapidly in chromium systems; iive-minute extractions being sufficient in hydrochloric acid systems and one-minute extractions in sulfuric acid media (Figure 29).

The extraction of chromium is materially decreased when the ratio of aqueous/organic phase volumes is increased (Figure 30). Such an effect is indicative of the relatively low extractability of the chromic acid adduct in comparison with that of mineral acids, as well as reflecting the increased dissociation of the $\mathrm{H}_{2} \mathrm{Cr}_{2} \mathrm{O}_{7}$ in dilute aqueous media. 


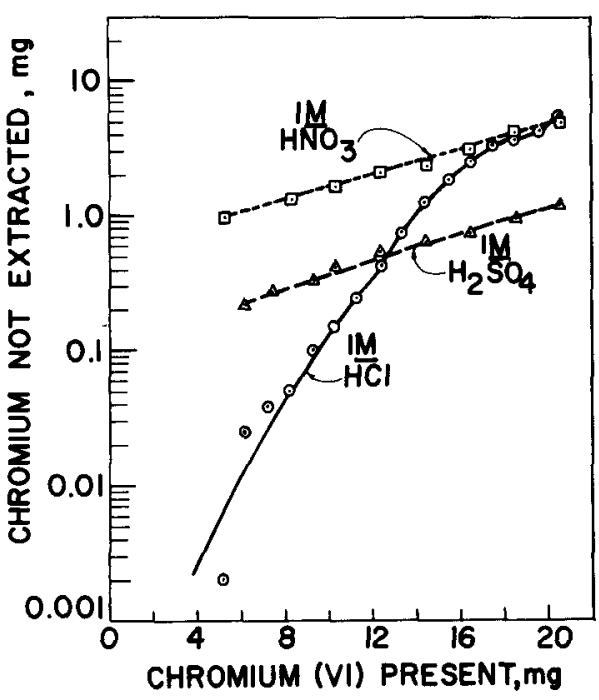

TIGURE 28. EXTRACTTON OF CFROMTIM(VI) WITE TRI-N-OCTYLPHOSPIIINE OXIDE AS A ITUNCTI ON OF CHRONITM CONCENTRATION. TOPO - $0.1 \mathrm{M}$ in cyclohexane, $5 \mathrm{ml}$; Phase ratio - J.; and Extraction time - 10 minutes.

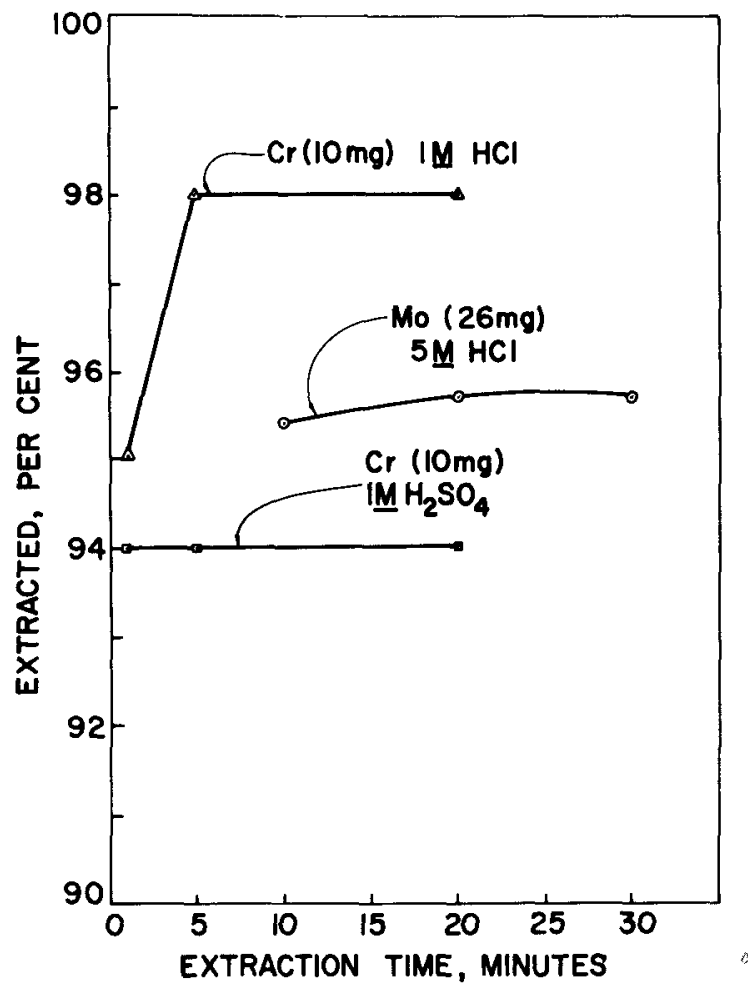

FIGURE 29. EXTRACTION OF CHROMIUM (VI) AND MOLYBDENUM(VI) WITH TRI-NOCTYLBHOSPHINE OXIDE AS A FUNCTION OF EXTRACTION TIME. TOPO - $0.1 \mathrm{M}$ in cyclohexane, $5 \mathrm{ml}$; and Phase ratio - 1.

Molybdenum. Molybdenum(VI) is extracted from mineral acid solutions in a variation of manners that reflect the complexity of aqueous solutions of molybdenum. The degree of extraction is cependent on the type of acid present as well as on the concentration of acid over a wide range (Fig. 3I). Extraction of molybdenum occurs readily from dilute solutions ( $\mathrm{pH} \sim \mathrm{l}$ ) of hydrochloric, sulfuric, nitric, and perchloric acids. Under these conditions molybdenum is probably extracted as the adduct of $\mathrm{H}_{6} \mathrm{MOO}_{6}$ or some more highly condensed acid where the ratio of Mo/TOPO is > 1 . Conditions are not attractive for separation purposes, however, since the organic phase is frequently turbid and the extracted adduct undergoes change on standing and assumes the blue color of mixed tetra- and hexavalent molybdenum species.

The extraction of molybdenum from nitric and perchloric acid solutions is continually decreased as the acid concentration is increased. 


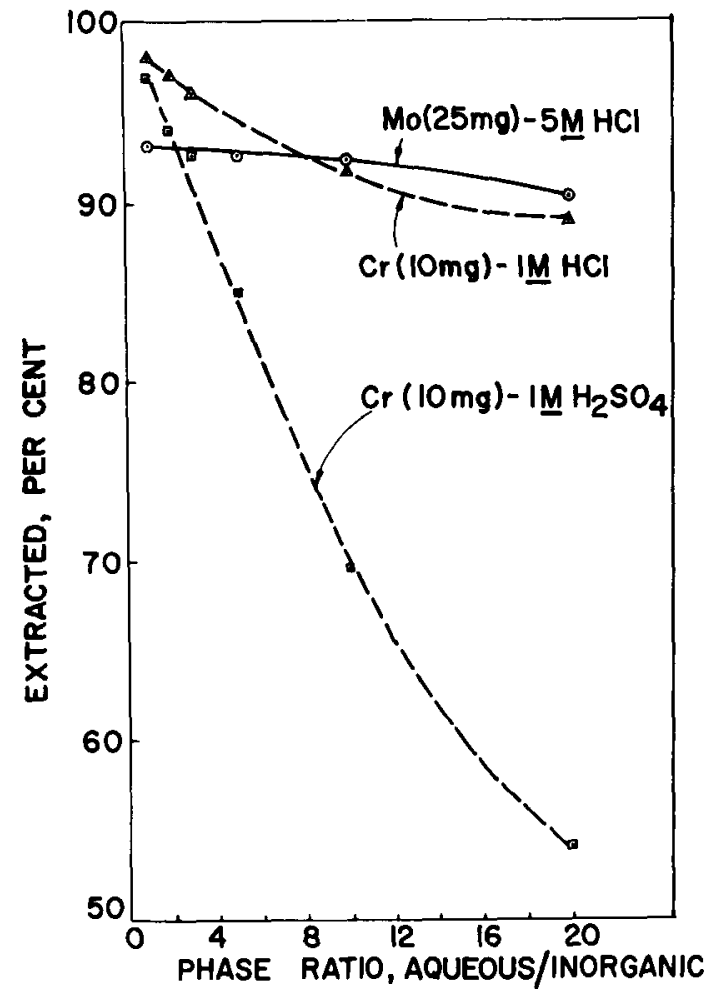

FIGURE 30. EXTRACTION OF MOLYBDENUM(VI) AND CHROMUM(VI) WITH TRIN-OCTYLPHOSPHINE OXIDE AS A FUNCTION OF PHASE RATIO. TOPO - $0.1 \mathrm{M}$ in cyclohexane, $5 \mathrm{ml}$; and Extraction time - 10 minutes.

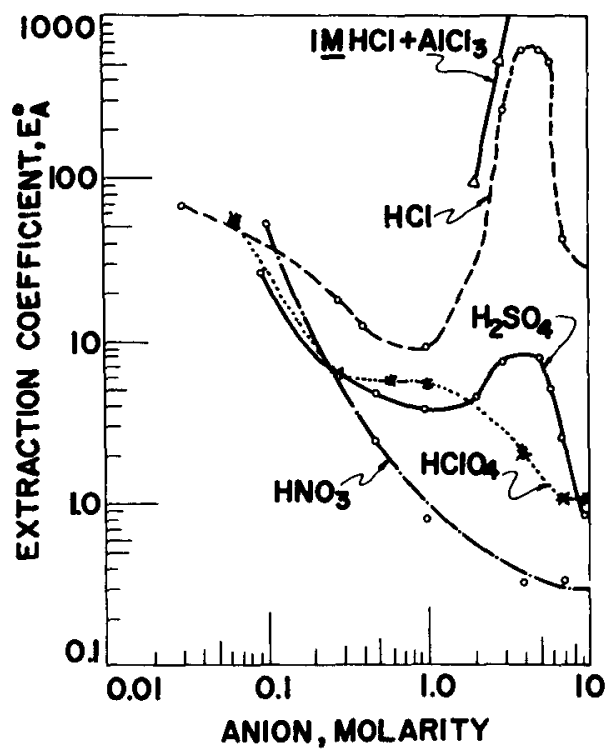

FIGURE 31. EXTRACTION OF MOLYBDENUM(VI) FROM ACIDIC SOLUTIONS WITH TRI-N-OCTYIPHOSPHINE OXIDE AS A FUNCTION OF ACID CONCENTRATION. $\mathrm{No}^{+6}-19.8 \mathrm{mg}$; TOPO - $0.1 \mathrm{M}$ in cyclohexane, $5 \mathrm{ml}$; Phase ratio - 1; and Equilibration time - 10 minutes.

In chloride and sulfate systems, the degree to which molybdenum is extracted decreases to a minimum as the acid concentration is increased from $\mathrm{pH} \sim \mathrm{I}$ to $\mathrm{I} \mathrm{M}$ and then attains a maximum in 4 to $5 \underline{M}$ acid media before decreasing again in more concentrated acid solutions. In chloride systems the extracted species is thought to be $\mathrm{MOO}_{2} \mathrm{Cl}_{2} \cdot 2$ (TOPO) and the extraction coefficient to reflect the concentration of $\mathrm{MOO}_{2} \mathrm{Cl}_{2}$ in aqueous systems that contain molybdenum species that vary within the general cationic form of $\mathrm{MOO}(\mathrm{OH})_{n} \cdot \mathrm{Cl}^{4-n}$. The extremely high extractability of this species is evident from the fact that $0.5 \mathrm{millimole}$ of TOPO is 96 per cent saturated in a single 10-minute equilibration with a $5 \mathrm{M}$ HCl solution that contains a stoichiometric amount (24 mg) of molybdenum (Figure 32). Although 4 to $5 \mathrm{M} \mathrm{HCl}$ solutions are most favorable for the extraction of molybdenum, 
complete extraction of $<20 \mathrm{mg}$ of molybdenum is achieved from 2 to $6 \mathrm{M} \mathrm{HCl}$ media or from $1 \underline{M} \mathrm{HCl}$ solutions that are at least $2 \underline{\mathrm{M}}$ in chlorlde.

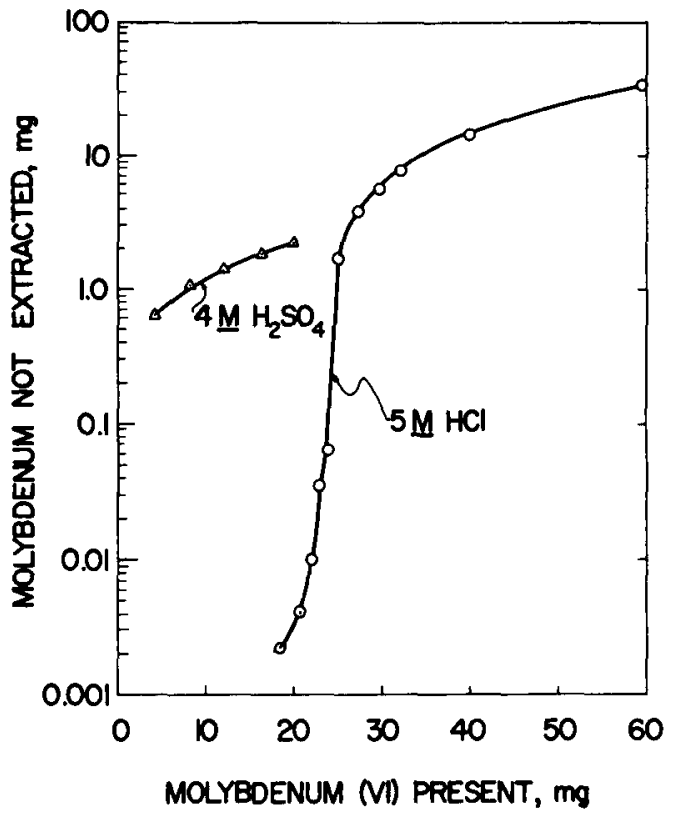

FIGURE 32. EXTRACTION OF MOLYBDENUM(VI) WITH TRI-N-OCTYLPHOSPHINE OXIDE AS A FUNCTION OF MOLYBDENUM CONCENTRATION. TOPO $-0.1 \mathrm{M}$ in cyclohexane, $5 \mathrm{ml}$; Phase ratio - 1 ; and Extraction time - 10 minutes.

Ten-minute extraction times are sufficient to achieve phase equilibration (Figure 29). The extractability of the molybdenum chloride adduct is virtually not affected by variations of the aqueous/organic phase volume ratio from 1 to 20 (Figure 30 ).

Although the extraction characteristics of molybdenum in sulfate systems roughly parallel those in chloride media, complete extraction is not achieved from sulfate solutions. A third, intermediate, phase is formed in $>10 \mathrm{M} \mathrm{H}_{2} \mathrm{SO}_{4}$ systems and contains a molybdenum species that changes from colorless to blue on standing.

Under optimum conditions, $4 \mathrm{M} \mathrm{H}_{2} \mathrm{SO}_{4}$, the magnitude of the extraction coefficient increases as the amount of molybdenum in the original aqueous phase is increased, and the saturation capacity of 0.5 millimole of Topo is in excess of $33 \mathrm{mg}$. These anomolies are indicative of the formation of adducts with TOPO/molybdenum mole ratios of less than 2 .

The extraction of molybdenum from nitrate or sulfate solutions is significantly enhanced by the addition of chloride to the solution. 
Complete extraction of $8 \mathrm{mg}$ of molybdenum has been achieved from 1 to $5 \mathrm{M}$ $\mathrm{H}_{2} \mathrm{SO}_{4}$ with $5 \underline{\mathrm{M}} \mathrm{HCl}$ or $5 \underline{\mathrm{M}} \mathrm{NaCl}$ and from $1 \underline{\mathrm{M}} \mathrm{HNO}_{3}$ solutions with $5 \underline{\mathrm{M}} \mathrm{NaCl}$ but not with $5 \mathrm{M} \mathrm{HCl}$.

Molybdenum has been back-extracted quantitatively from cyclohexane solutions of TOPO with solutions of $2 \mathrm{~N} \mathrm{NH}_{4} \mathrm{OH}$.

Extraction of Elements in Feriodic Group VII

Manganese. Divalent manganese is not extracted $\left(E_{a}^{\circ}<0.01\right)$

from 0.5 to $7 \underline{\mathrm{M} \mathrm{HCl}}$, $\mathrm{HNO}_{3}$, or $\mathrm{H}_{2} \mathrm{SO}_{4}$.

Manganese(VII) in mineral-acid solutions is a strong oxidant and is rapidly reduced to lower oxidation states when equilibrated with cyclohexane solutions of TOPO. Essentially quantitative extraction of $10 \mathrm{mg}$ of manganese(VII) occurs from $0.1 \mathrm{M}$ acid solutions; however, the extracted adduct is quickly reduced to a krown, insoluble species that precipitates at the phase interface. Extraction is decreased in sulfate systems as the concentration of sulfuric acid is increased. Practically all of the manganese(VII) is retained in the aqueous solution of a $7 \underline{M}$ $\mathrm{H}_{2} \mathrm{SO}_{4}$ system but is converted to a colorless species after standing a few hours. In hydrochloric acid systems, the species extracted from $5 \underline{M}$

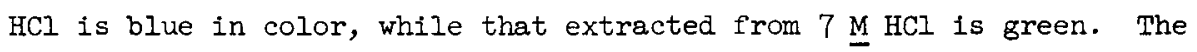
organic phases of these systems are also decolorized with standing. Rapid reduction of manganese(VII) to insoluble manganese dioxide occurs in 0.1 to $7 \underline{\mathrm{M}} \mathrm{HNO}_{3}$ systems.

Technetium. An extensive study of the extraction characteristics of technetium has been reported by Boyd and Larson. (2) These investigators used the 60-day gamma emitter, technetium-95 m, for radiometric studies and the $2.2 \times 10^{5}$-year beta emitting isotope, technetium-99 $\mathrm{g}$, for extractions where the technetium concentration was $10^{-4}$ to $10^{-6} \mathrm{M}$.

Technetium is extracted readily with 0.1 M solutions of TOPO in cyclohexane from 1 M solutions of phosphoric acid $\left(E_{\mathrm{a}}^{O}=130\right)$, sulfuric acid $\left(E_{\mathrm{a}}^{\circ}=51\right)$, hydrochloric acid $\left(E_{\mathrm{Q}}^{\circ}=48\right)$, and hidrobromic acid $\left(E_{\mathrm{Q}}^{\circ}=25\right)$. Essentially complete extraction $\left(F_{\mathrm{a}}^{\circ}=65\right)$ is also achieved from 1 M HI 
solutions; however, heptavalent technetium tends to be unstable in the presence of such a reducing agent as hydriodic acid. In sulfate systems the extraction is decreased markedly $\left(E_{a}^{O}=0.017\right)$ by substitution of $1 M$ $\mathrm{Na}_{2} \mathrm{SO}_{4}$ for $1 \mathrm{M} \mathrm{H}_{2} \mathrm{SO}_{4}$. The extraction from $1 \underline{\mathrm{M}} \mathrm{HNO}_{3}\left(\mathrm{E}_{\mathrm{a}}^{\circ}=0.46\right)$ or $1 \mathrm{M}$ $\mathrm{HClO}_{4}\left(\mathrm{E}_{\mathrm{a}}^{\circ}=0.24\right)$ is much less than that achieved from the other mineral acids. In nitric acid systems, as in other inorganic acid media, maximum extraction is obtained when the concentration of acid is $1 \mathrm{M}$ or less (Figure 32a). The detrimental effect of increased acid concentration

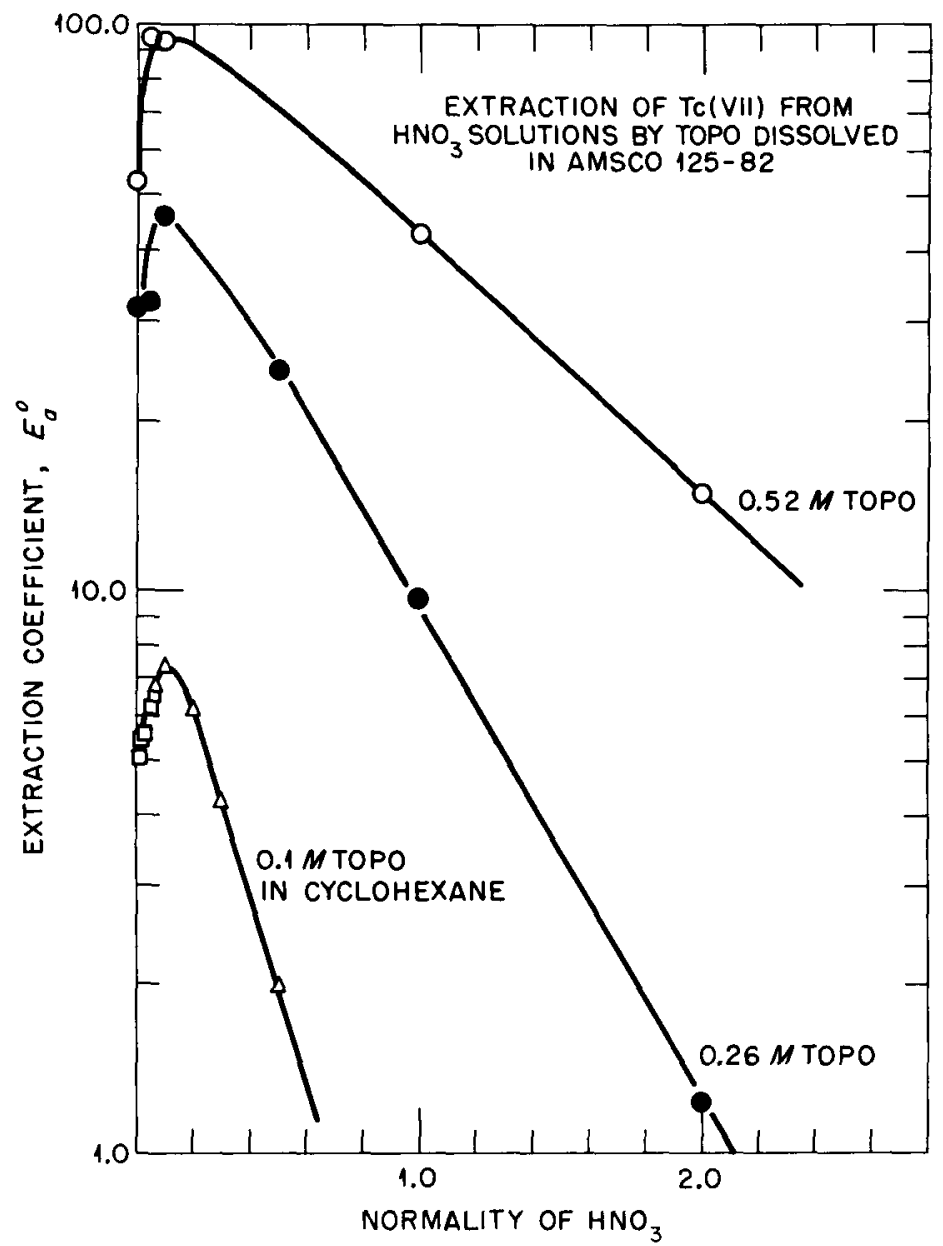

FIGURE 32a. EXTRACTION OF TECHNETIUM FROM NITRIC ACID SOLUTIONS WITH CYCLOHEXANE SOLUTIONS OF TRI-N-OCTYLPHOSPHINE OXIDE

is considered to be due to an exchange of anions in the extracted adduct between the technetium species, $\mathrm{HTCO}_{4} \cdot 2$ (TOPO), and the mineral acid.

The extraction of technetium with TOPO is independent of variations 
in the phase volumes. Small changes in the extraction coefficient, 5.2 per cent per degree at $25^{\circ} \mathrm{C}$, were observed in systems that contalned 10 per cent TOPO solutions when the temperature of the system was varied. Very little information is available on the extraction characteristics of lower oxidation states of technetium. Boyd and Larson have shown that the thiocyanate complex of technetium(V) is extracted quantitatively from chloride solutions with TOPO. The very high molar absorptivity of the extracted species in the visible region makes such an extraction attractive as a means of detecting technetium.

Extraction of Elements in Periodic Group VIII.

Iron. (10) Divalent iron is not extracted, as such, by cyclohexane solutions of TOPO. Iron(II) is partially oxidized when acid solutions are equilibrated with cyclohexane solutions of TOPO unless the system also contains a strong reducing agent and an inert atmosphere.

Iron(III) is extracted with TOPO only from chloride solutions. The degree of extraction increases with the concentration' of chloride in the aqueous phase although some hydrogen ions must also be present (FIg. 33). The amount of iron extracted is proportional to the amount of TOPO present since the extracted species has been shown to be $\mathrm{FeCl}_{3} \cdot 2$ (TOPO). Although varying amounts of hydrochloric acid are co-extracted with the iron-TOPO adduct, the preponderance of experimental evidence is against the possibility that the adduct is actually $\mathrm{HFeCl}_{4} \cdot 2$ (TOPO).

Complete extraction of as much as 12 IIg of fron(III) can be achieved from $7 \mathrm{M} \mathrm{HCl}$ in a single, 10-minute equilibration with $0.5 \mathrm{millimole}$ of TOPO (Figure 34). This amount of iron is equivalent to $\sim 80$ per cent of the saturation capacity of 0.5 millimole of TOPO. Equilibrium is attained rapidly, although extractions are usually carried out for 10 minutes.

Extraction of as much as $10 \mathrm{mg}$ of iron is complete even when the aqueous/organic phase ratio is increased from 1 to 20 (Figure 35).

Although iron(III) is not extracted from sulfuric, nitric, phosphoric, or perchloric acids in the absence of chloride, signiflcant extraction is 


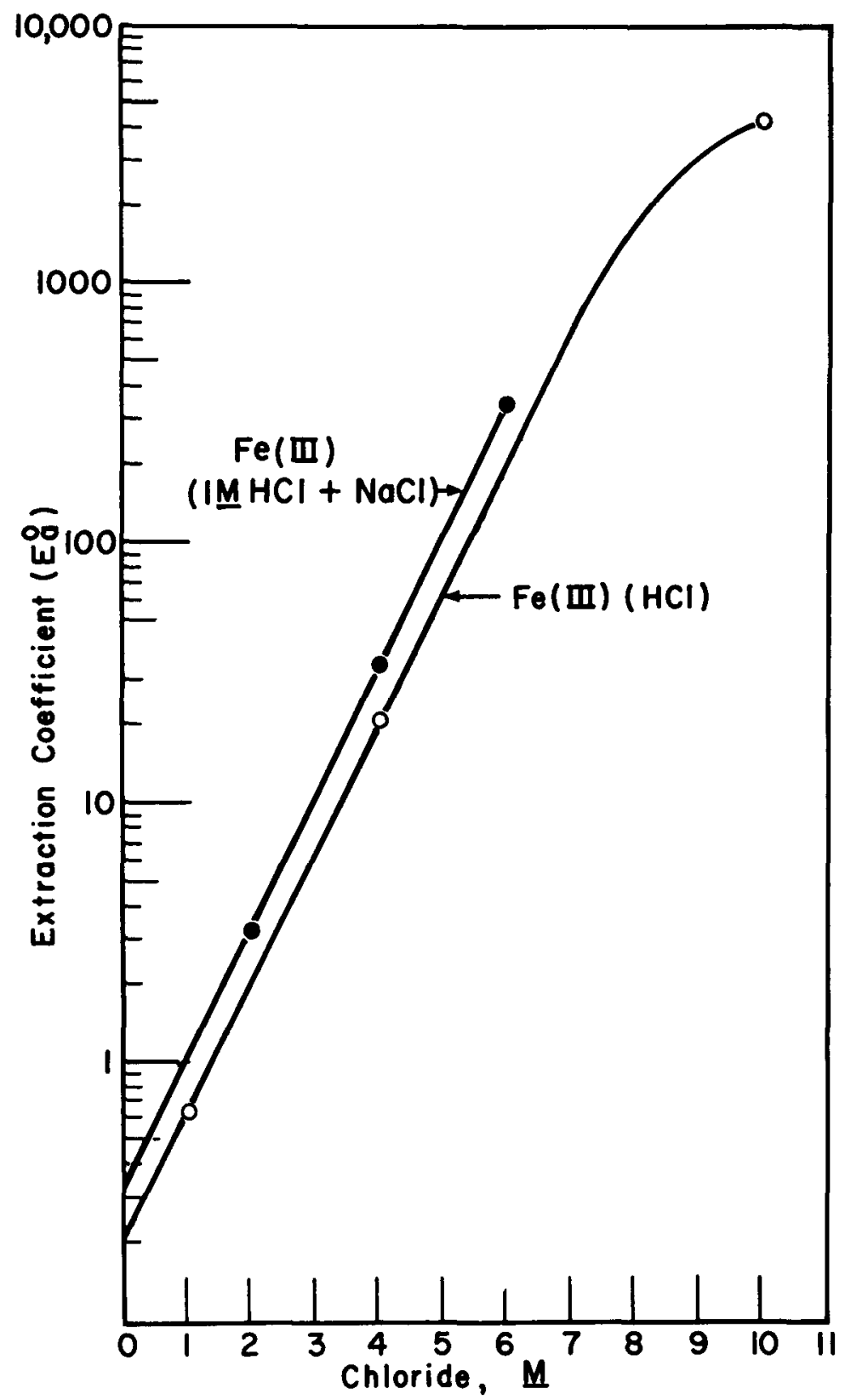

FLUUPE 33. LXPPACTI ON OT TROY FROM CHLORIDE SOI,UTIONS WITH TRI-N_CCTYLPHISPIIND OXTDE. Fe - $9 \mathrm{mg}$; TOPO - 0.J II in crolohexane, $5 \mathrm{ml}$; Phase ralio - 1 ; ind Ixtraction Eime Jo minutes. 
achieved from these media when chloride is added. For instance, $10 \mathrm{mg}$ of iron is extracted completely from solutions that are 1 to $3 \mathrm{M}$ in $\mathrm{H}_{2} \mathrm{SO}_{4}$ and $7 \underline{\mathrm{M}}$ in $\mathrm{HCl}$ or $3 \underline{\mathrm{M}}$ in $\mathrm{H}_{2} \mathrm{SO}_{4}$ and $3 \underline{\mathrm{M}}$ in $\mathrm{NaCl}$, while $10 \mathrm{mg}$ of 1 ron is 92 per cent extracted from 1 to $3 \underline{\mathrm{M}} \mathrm{HNO}_{3}$ and $7 \underline{\mathrm{M}} \mathrm{HCl}$.

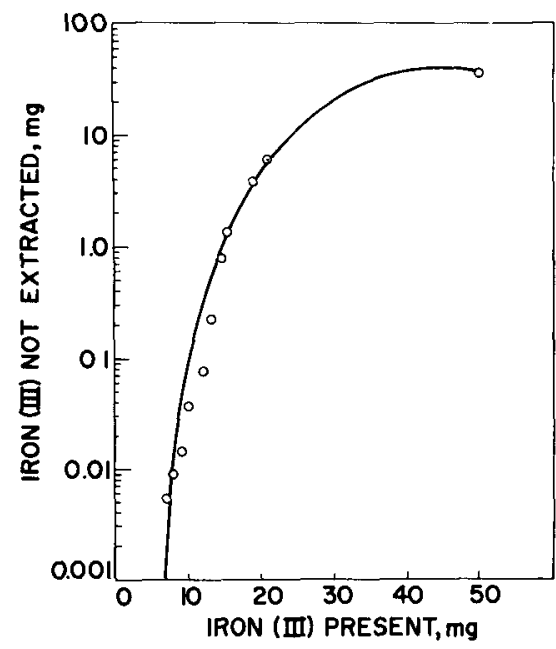

FIGURE 34. EXTRACTION OF IRON(III) WITH TRI-N-OCTYLPHOSPHINE OXIDE AS A FUNCTION OF CONCENTRATION OF IRON(III)。 $\mathrm{HCl}-7 \mathrm{M}$; TOPO - $0.1 \mathrm{M}$ in cyclohexane, $5 \mathrm{ml} \overline{\text {; }}$ Phase ratio $=$ 1 ; and Extraction time - 10 minutes.

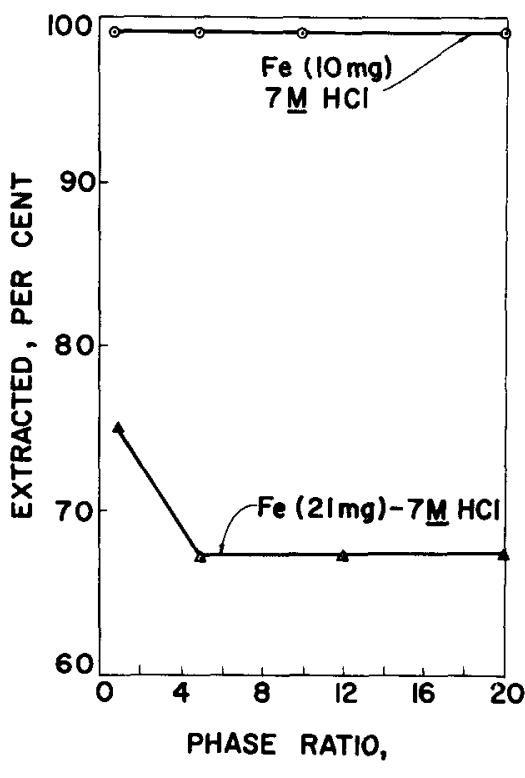

AQUEOUS / ORGANIC

FIGURE 35. EXTRACTION OF IRON(III) WITH TRI-N-OCTYLPHOSPHINE OXIDE AS A FUNCTION CF PHASE RATIO. TOPO $0.1 \mathrm{M}$ in cyclohexane, $5 \mathrm{ml}$; and Extraction time - 10 minutes.

Cobalt. On the basis of qualitative results, cobalt(II) is not extracted from acidic solutions with TOPO.

Nickel. Nickel(II) is not extracted with cyclohexane solutions of TOPO from acid chloride, nitrate, sulfate, or perchlorate meda.

Ruthenium. The extraction of ruthenium(III, IV) from chloride, nitrate, sulfate or perchlorate media, as based on qualitative results, is essentially nil.

Platinum. Platinum(IV) is partially extracted from acid chloride and chloride-sulfate solutions with TOPO.

\section{Extraction of the Rare-Earth Elements}

On the basis of qualitative results obtained by the authors from 
the extraction of synthetic solutions of rare-earth elements, no extraction of these elements occurs from 1 or $7 \mathrm{M} \mathrm{HCl}, \mathrm{H}_{2} \mathrm{SO}_{4}, \mathrm{HClO}_{4}$, or $\mathrm{HrO}_{3}$. Other investigators have found that rare-earth elements are partially extracted with kerosene solutions of TOPO from very dilute acid solutions (Table III). (12) The extraction is enhanced by the addition of aluminum nitrate to the aqueous solution, but is decreased when the concentration of nitric acid is increased.

TABLE III

EXTRACTION OF RARE-EARTH ELFMUENTS FROM NITRATE SOLUTIONS

\begin{tabular}{|c|c|c|}
\hline Element & $\begin{array}{l}\text { Rare-Earth Oxide } \\
\text { Present, } \mathrm{mg} / \mathrm{ml}\end{array}$ & $\mathrm{E}_{\mathrm{Q}}^{O}$ \\
\hline$Y$ & 1.95 & 0.43 \\
\hline $\mathrm{La}$ & 2.50 & .35 \\
\hline $\operatorname{Pr}$ & 1.87 & .81 \\
\hline Nd & 1.95 & .95 \\
\hline $\mathrm{Sm}$ & 2.01 & 1.38 \\
\hline Gd & 1.91 & 1.12 \\
\hline
\end{tabular}

The same investigators have shown that partial separations of rareearth elements from one another and from yttrium can be achieved by extraction with roPO from nitrate solutions of mixed rare-earth elements $(3)$ (Table IV).

TABLE IV

SEPARATION OF RARE-EARTH ELEMENISS FROM YITIRTUM

TOPO - $0.1 \mathrm{M}$ in kerosene

Phase ratio- 1

Element

$\mathrm{E}_{\mathrm{a}}^{\mathrm{O}}$

Separation Factor, $M / Y$

$1 \mathrm{M} \mathrm{HNO}_{3} 0.5 \mathrm{M} \mathrm{HNO}_{3} \mathrm{pHI} \quad 1 \mathrm{MHNO} 30.5 \mathrm{M} \mathrm{HNO}_{3} \mathrm{PHI}$

$\begin{array}{lcccccc}\text { Y } & 0.19 & 0.376 & 0.334 & - & - & - \\ \text { Gd } & .40 & 1.23 & 0.32 & 2.2 & 3.3 & 4.0 \\ \text { Tb } & .25 & 0.916 & - & 1.3 & 2.46 & - \\ \text { Dy } & .32 & 1.18 & 1.18 & 1.7 & 3.1 & 3.5 \\ \text { Ho } & .24 & 0.79 & 0.90 & 1.3 & 2.1 & 2.7 \\ \text { Er } & .18 & .65 & .68 & 1.0 & 1.7 & 2.0 \\ \text { Tm } & .12 & .44 & - & 0.6 & 1.17 & - \\ \text { Yb } & .16 & .36 & 0.42 & .16 & 0.96 & 1.26\end{array}$

By means of radiochemical techniques, Weaver has shown that the extraction coefficient of europium passes through a maximum as the nitric acid 
concentration is increased fram $0.02 \mathrm{M}$ to $12 \mathrm{M}$, as show in Table V. (14) Tridecylalcohol, 4 per cent, was added to minimize third phase formation.

TABLE V

EXIRACTION OF EUROPIUM FROM NITRIC ACID SOLUTIONS

\begin{tabular}{cc} 
TOPO - $0.3 \mathrm{M}$ in Amsco \\
$\mathrm{HNO}_{3}, \mathrm{M}$ & $\underline{\mathrm{E}_{\mathrm{a}}^{\mathrm{O}}}$ \\
\hline 0.02 & 0.2 \\
0.05 & 1.5 \\
0.1 & 4 \\
0.2 & 9 \\
0.5 & 10 \\
1.0 & 5 \\
2.0 & 1 \\
5.0 & 0.05 \\
7.0 & 0.02 \\
10 & 0.01 \\
12 & 0.03
\end{tabular}

The degree of extraction was very greatly enhanced by the addition of $0.6 \mathrm{M} \mathrm{Na}_{2} \mathrm{SO}_{4}$ and $3.9 \mathrm{M} \mathrm{NaNO}_{3}$; the extraction coefficients in $0.01 \mathrm{M}$ and $0.1 \mathrm{M} \mathrm{NNO}_{3}$ systems being 31 and $>1000$. Similar enhancement is achleved in the extraction of neodymium and cerium(III).

Cerium(IV) is extracted readily with TOPO from acid nitrate solutions, to a lesser extent from sulfate media, and poorly from solutions that contain chloride (Figure 36). Compiete extraction from acid solutions cannot be achieved in a single equilibration because cerium(IV) is partially reduced to the non-extractable trivalent state during equilibration. Extended extraction times impair, rather than enhance, the extraction (Fig.37).

The degree of extraction of cerium from nitric acid solutions is not dependent on the concentration of acid. When a solution that 1 s $I M$ in $\mathrm{HNO}_{3}$ is made $2 \underline{\mathrm{M}}$ in nitrate by the addition of sodium nitrate, the extraction of $21 \mathrm{mg}$ of cerlum is reduced from 97 to 95 per cent. As the concentration of sodium nitrate is increased, the extraction is enhanced until 97 per cent extraction is again achieved from $1 \mathrm{M} \mathrm{HNO}_{3}$ solutions that are also $7 \mathrm{M}$ in nitrate. These data lead to the postulation that the extracted species is $\mathrm{H}_{2} \mathrm{Ce}\left(\mathrm{NO}_{3}\right)_{6} \cdot 2$ (TOPO). An amount of cerlum (35 ms) that 
is equivalent to the saturation capacity of 0.5 millimole of ToPo can be extracted to an extent greater than 95 per cent in a single extraction. Essentially complete extraction can be obtained if the raffinate is boiled with a strong oxidant, such as AgO, and re-extracted with a fresh solution of TOPO.

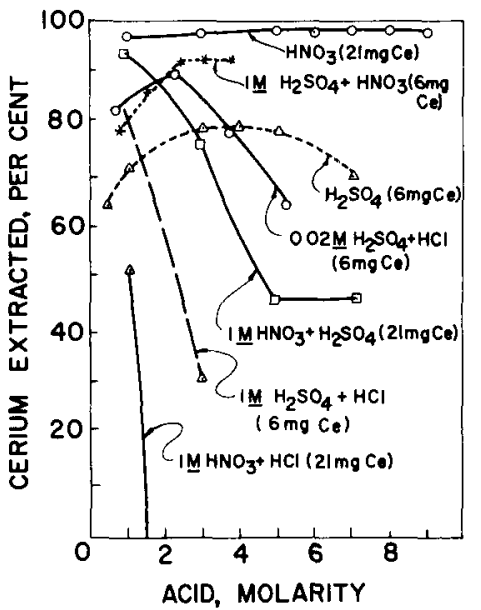

FIGURE 36. EXTRACTION OF CERIUM(IV) WITH TRI-N-OCTYLPHOSPHINE OXIDE AS A FUNCTICN OF ACID CONCENTRATION. TOPO - $0.1 \mathrm{M}$ in cyclohexane, $5 \mathrm{ml}$; Phase ratio- - 1; and Extraction time -5 minutes.

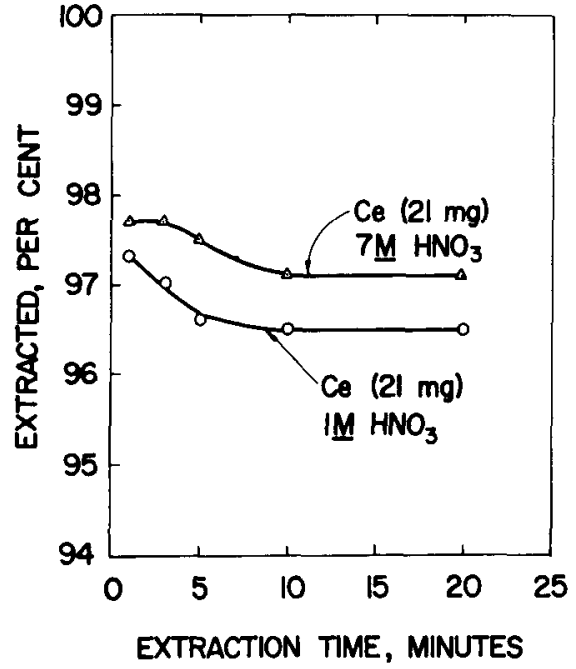

FIGURE 37. EXTRACTION OF CERIUM(IV) WITH TRI-N-OCTYLPHOSPHINE OXIDE AS A FUNCTION OF EXTRACTION TIME. TOPO - $0.1 \mathrm{M}$ in cyclohexane, $5 \mathrm{ml}$; and Phase rätio - 1 .

Extraction of cerium(IV) from $I$ or $7 \underline{\mathrm{M}} \mathrm{HNO}_{3}$ is decreased when the phase ratio, aqueous/organic, is increased (Figure 38 ).

Cerium is extracted from acidic sulfate solutions to a much lesser degree than from nitrate media. Extraction is most favored in 3 to $5 \underline{M}$ $\mathrm{H}_{2} \mathrm{SO}_{4}$; however, only 80 per cent extraction of $6 \mathrm{mg}$ of cerium can be achieved. The decrease in extraction is due not only to partial reduction of cerate to cerous, but to the formation of sulfate species that are less extractable than those present in nitrate systems. When sodium sulfate is added to a $1 \mathrm{M} \mathrm{H}_{2} \mathrm{SO}_{4}$ solution that contains $6 \mathrm{mg}$ of cerium(IV) the extraction is decreased continuously, and unreduced cerium(IV) remains in the aqueous phase.

Cerium(IV) is reduced to the trivalent state in hydrochloric acid 
media; the reaction is quantitative in $7 \underline{\mathrm{M}} \mathrm{HCl}$ solutions. Consequently, the presence of chloride in nitrate or sulfate solutions of cerium only expedites the reduction of cerium(IV) and, thus, decreases the concentration of the extractable species.

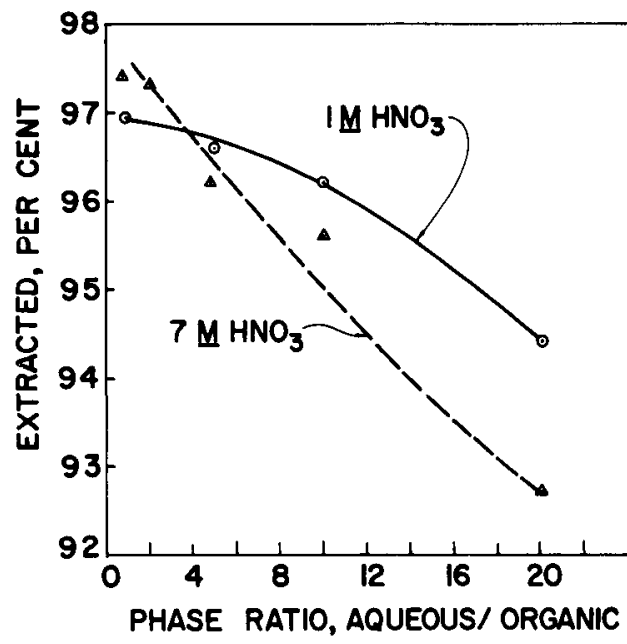

FIGURE 38. EXTRACTION OF CERIUM(IV) WITH TRI-N-OCTYLPHOSPHINE OXIDE AS A FUNCTION OF PHASE RATIO. Cerium - $21 \mathrm{mg}$; TOPO - $0.1 \mathrm{M}$ in cyclohexane, $5 \mathrm{ml}$; and Exträction time - 10 minutes.

Extraction of Thorium (1I)

The degree of extraction of thorium is very dependent on the type and concentration of inorganic acid in the aqueous phase (Figure 39). Thorium is extracted completely from dilute nitric acid solutions; however, the extraction is impaired, through co-extraction of the mineral acid, when the acid concentration is increased. In acidic chloride systems, the effect of the concentration of acid is reversed; maximum extraction is achieved from 5 to $7 \underline{\mathrm{M}} \mathrm{HCl}$, while very poor extraction occurs in more dilute acid systems. The degree of extraction of thorium from perchloric acid solutions passes through a minimum in $3 \mathrm{M} \mathrm{HClO}_{4}$ media when the acid concentration is varied from 0.5 to $7 \underline{\mathrm{M}}$. Extraction is essentially complete from $0.5 \underline{\mathrm{M}}$ and $>6 \mathrm{M} \mathrm{HClO}_{4}$. Systems that contain $>5 \underline{\mathrm{M}} \mathrm{HClO}_{4}$ are not favorable for analytical separations of thorium because a third, intermediate phase frequently occurs when the solubility of the metal and acld adducts in cyclohexane are exceeded.

Thorium is extracted only slightly from $>1 \underline{\mathrm{M}_{2}} \mathrm{H}_{2} \mathrm{SO}_{4}$ and not at all 


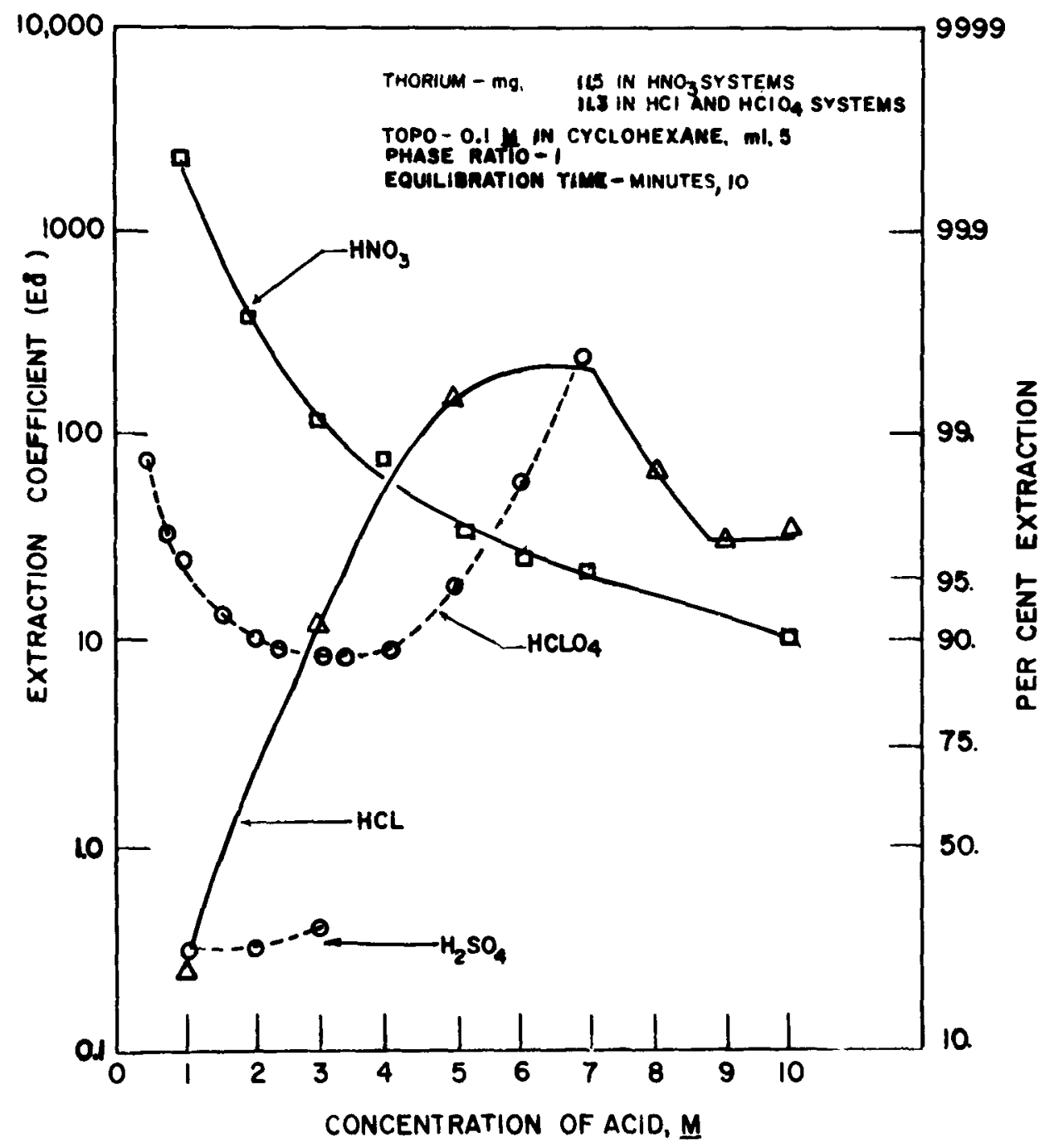

FIGURE 39. EFFECT OF CONCENTIRATION OF ACID ON THE EXTRACTION OF THORIUM WITH TRI-N-OVTYLPHOSPHINE OXIDE

from more dilute acid solutions. Consequently, thorium is quantitatively stripped from cyclohexane solutions by back-extraction with $0.3 \mathrm{M} \mathrm{H}_{2} \mathrm{SO}_{4}$. The adduct is hydrolyzed by very dilute, < $0.1 \underline{M}$, sulfuric acid.

Thorium is completely extracted from solutions that are as much as $8 \mathrm{M}$ in nitrate when the hydrogen ion concentration of the aqueous phase is maintained at 0.5 or 1 M (Figure 40). The species that is extracted from nitrate media, $\mathrm{Th}\left(\mathrm{NO}_{3}\right)_{4} \cdot 2(\mathrm{TOPO})$, is affected, therefore, only by the coextraction of nitric acid. Substitution of chloride salts in 1 systems yields extraction simflar to that achleved from hydrochloric acid 


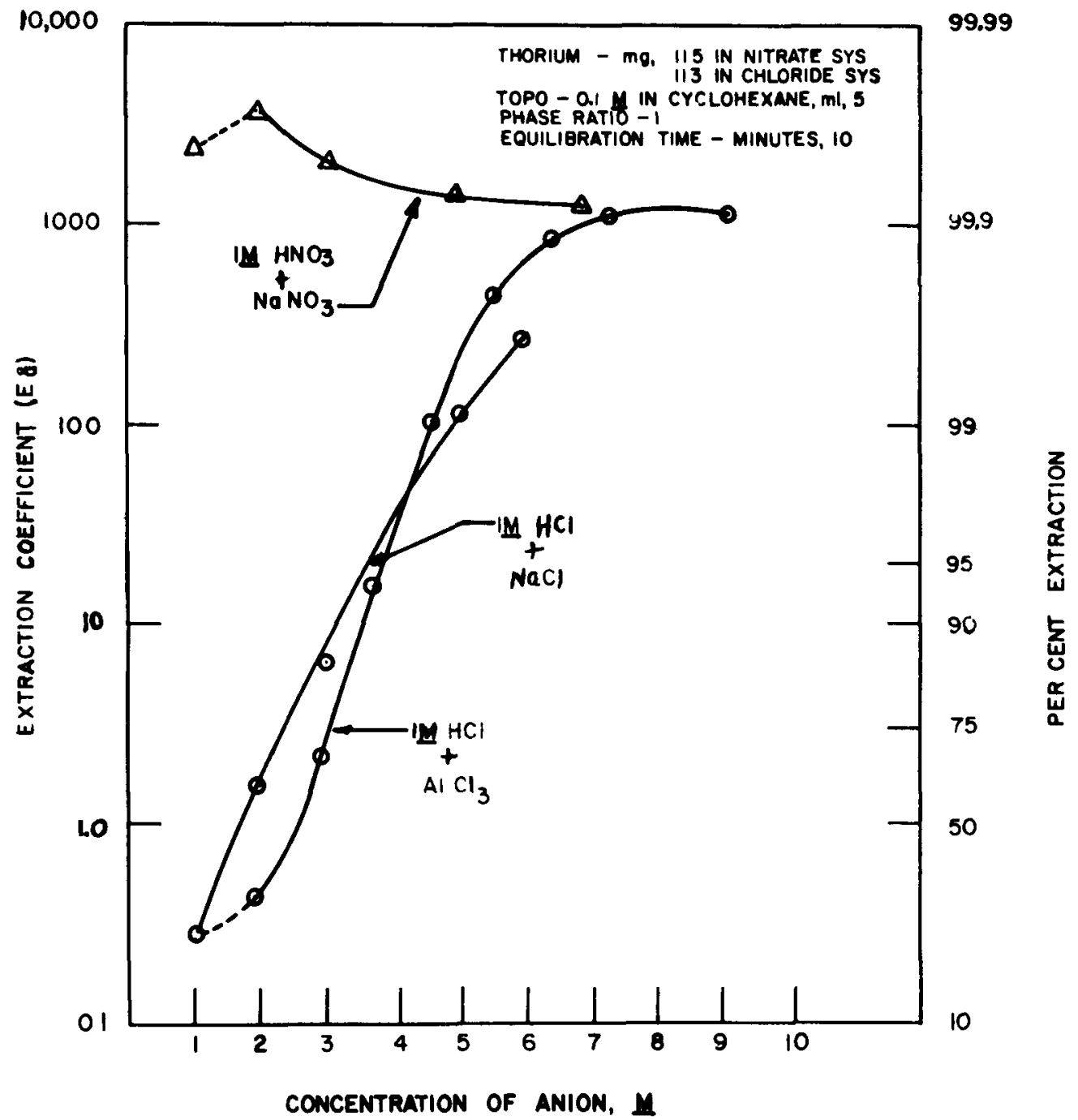

FIGURE 40. EFFECT OF CONCENTRATION OF CHLORIDE AND NITRATE ON THE EXTRACTION OF THORIUM WITH TRI-N-OCTYLPHOSPHINE OXIDE

solutions of the same chloride concentration. Formation of the extractable species, $\mathrm{ThCl}_{4} \cdot 3$ (TOPO), is favored at relative high concentrations of chloride in the aqueous phase. Saturation of TOPO with thorium is not achieved, even in the presence of ten-fold excess thorium in the aqueous phase, because of the relatively high extractability of the hydrochloric and nitric acid. The mole ratios found in the organic phases of $1 \mathrm{M} \mathrm{HNO}_{3}$ systems are $\mathrm{NO}_{3} / \mathrm{Th}, 5.3$; and $\mathrm{TOPO} / \mathrm{Th}, 3.0$, while in 5 to $7 \mathrm{M} \mathrm{HCl}$ systems the ratio of chloride/Th is 4.2 and the ratio of TOPO/Th 1s 3.3. As much 
as $14 \mathrm{mg}$ of thorium is extracted completely from $7 \underline{\mathrm{M} \mathrm{HCl}}$ and $23 \mathrm{mg}$ of thorium from $1 \underline{\mathrm{M}} \mathrm{ENO}_{3}$ with 0.5 millimole of TOPO in a single, 10-minute equilibration (Figure 4I).

Extraction from nitric acid is more favorable than that from chloride media, because equilibrium is achieved in five minutes and less adverse effect results when phase ratio is increased above 1 (Figure 42). Thorium is readily concentrated from dilute solutions that are $I M$ in $\mathrm{KNO}_{3}$ by a single extraction.

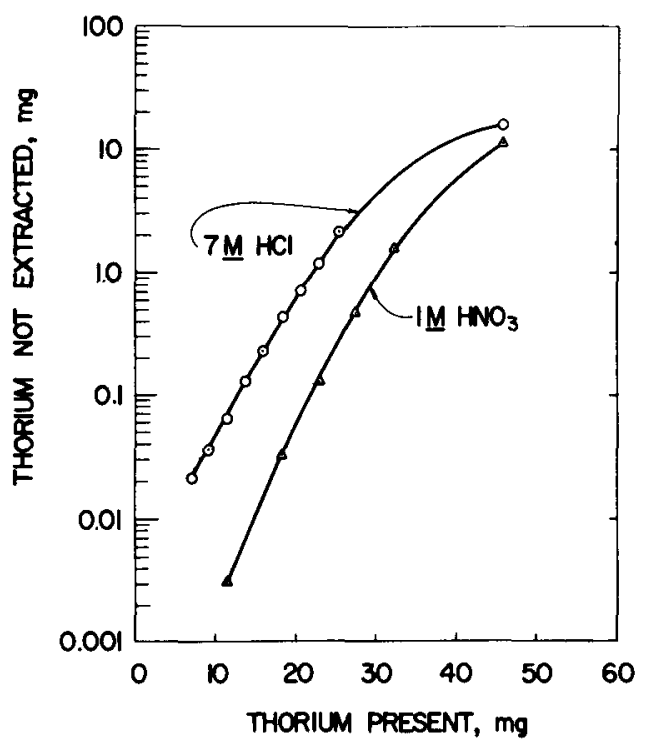

FIGURE 47. EXTRACTION OF THORIUM WITH TRI-N-OCTYLPHOSPHINE OXIDE AS A FUNCTION OF THORIUM CONCENTRATION. TOPO - $0.1 \mathrm{~m}$ in cyclohexane, $5 \mathrm{ml}$; Phase ratio - 1; and Extraction time - 10 minutes.

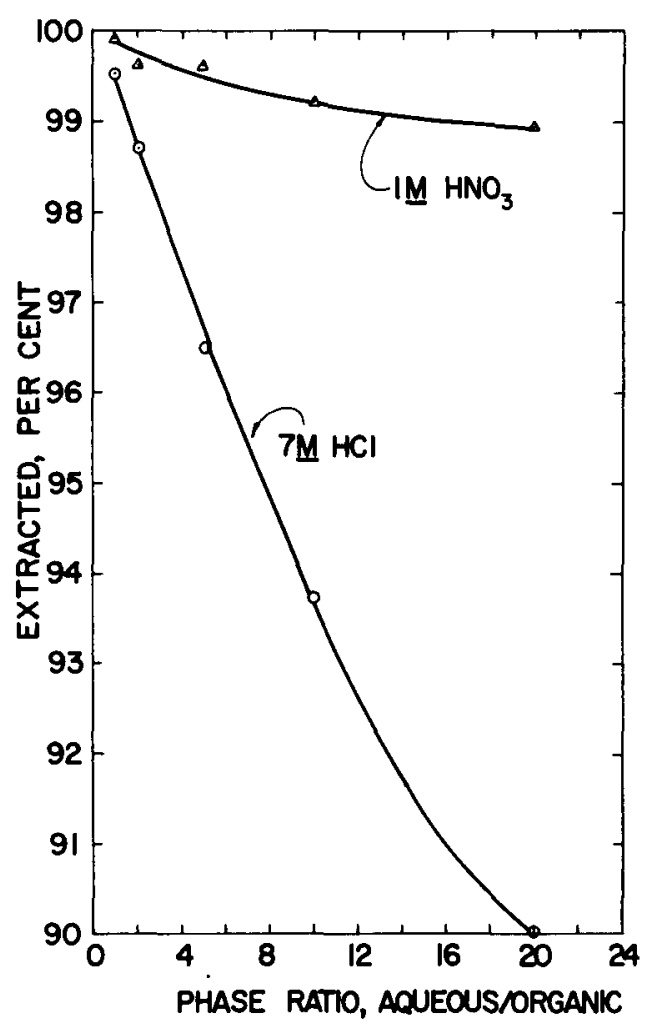

FIGURE 42. EXTRACTION OF THORIUM WITH TRI-N-OCTYLPHOSPHINE OXIDE AS A FUNCTION OF PHASE RATIO. Thorium - $12 \mathrm{mg}$; TOPO - $0.1 \mathrm{M}$ in cyclohexane, $5 \mathrm{ml}$; and Extraction time - 10 minutes.

Although the extraction of thorium is seriausly impaired by sulfate, and to an even greater extent by phosphate, marked enhancement is regained when nitrate is added to the aqueous solution (Figure 43). Extraction is complete from solutions that are (a) $2 \underline{\mathrm{M}}$ in $\mathrm{H}_{2} \mathrm{SO}_{4}$, (b) $0.2 \underline{\mathrm{M}}$ in $\mathrm{H}_{3} \mathrm{PO}_{4}$, or 
(c) $0.5 \mathrm{M} \mathrm{H}_{2} \mathrm{SO}_{4}$ and $0.1 \mathrm{M} \mathrm{H}_{3} \mathrm{PO}_{4}$ if the solution is also $0.5 \mathrm{M}$ in $\mathrm{HNO}_{3}$ and $4 \mathrm{M}$ in $\mathrm{NaNO}_{3}$. These limiting concentrations are easily attained by diluting concentrated solutions with $1 \mathrm{M} \mathrm{HNO}_{3}$. Sub-milligram amounts of thoriun are completely extracted with $5 \mathrm{ml}$ of $0.1 \mathrm{M}$ TOPO from $50 \mathrm{ml}$ of aqueous solutions that are $0.5 \underline{\mathrm{M}}$ in $\mathrm{H}_{2} \mathrm{SO}_{4}, 0.06 \mathrm{M}$ in $\mathrm{H}_{3} \mathrm{PO}_{4}, I \underline{\mathrm{M}}$ in $\mathrm{HNO}_{3}$, and $1 \underline{\mathrm{M}}$ in $\mathrm{NaNO}_{3}$.

The extraction characteristics of chorium, reported above, as determined by spectrophotometric analyses, have been duplicated, in part, with the use of a radio-tracer, thorium-234 (Figure 44). This radio-1sotope

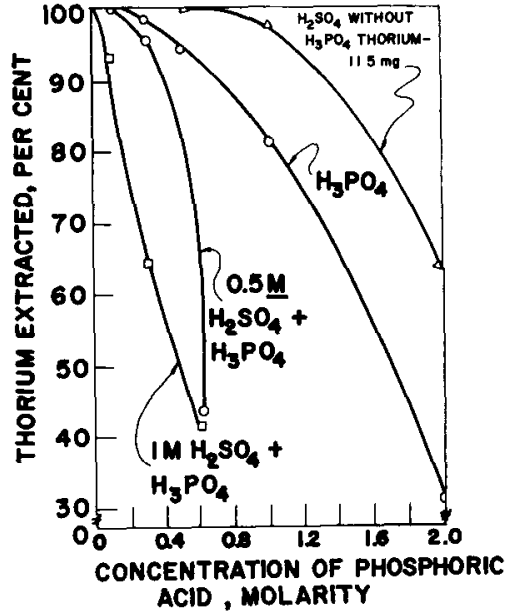

FIGURE 43. EFFECT OF SULFATE AND PHOSPHATE ON THE EXTRACTION OF THORIUM FROM NITRATE SOLUTIONS WITH TRI-N-OCTYLPHOSPHINE OXIDE. Thorium - $0.345 \mathrm{mg}$; TOPO - $0.1 \mathrm{M}$ in cyclohexane, $5 \mathrm{ml}$; $\mathrm{HNO}_{3}-0.5 \mathrm{~N}$; $\mathrm{NaNO}_{3}-4 \mathrm{M}$; and Phase ratio - 1 .

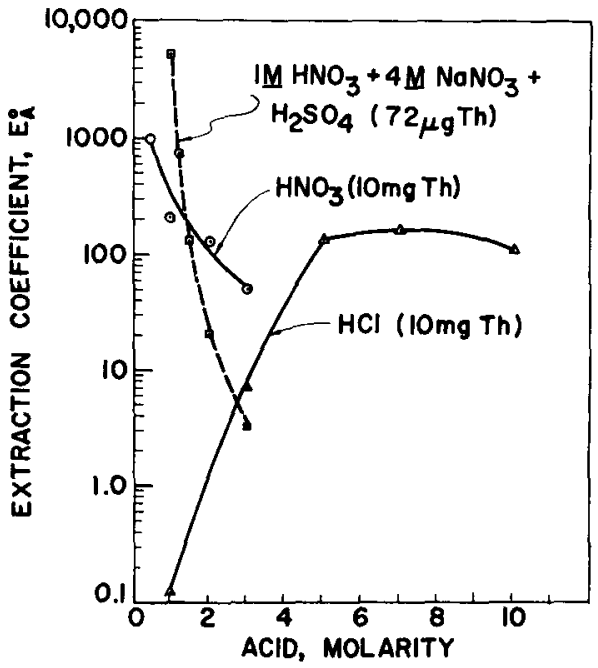

FIGURE 44. EXTRACTION OF THORIUM WITH TRI-N-OCTYLPHOSPHINE OXIDE RADIOTHORIUM-2 34 SYSTEMS. TOPO $0.1 \mathrm{M}$ in cyclohexane, $5 \mathrm{ml}$; Phase ratio - 1 ; and Extraction time 15 minutes.

was obtained from the Oak Ridge National Laboratory in a solution of $1.2 \underline{M}$

$\mathrm{HCl}$. The extraction characteristics of the tracer from hydrochloric acid solution were very erratic and inconclusive in the absence of a carrier. Carrier solutions were prepared by combining allquots of standard solutions of thorium-232 with aliquots of the thorium-234 solution and repeatedly evaporating to dryness from the desired acid before ultimately diluting to a known volume with $I \mathrm{M}$ acid. Aliquots removed for each extraction test contained $\sim 6 \times 10^{5} \mathrm{cpm}$ of gamma activity. The solutions of thorium- 
232 also emitted gamma photons due to a decay product that was only slightly extracted from hydrochloric or nitric acid with TOPO. The activity of the decay product was measured under identical conditions and used as correction factors for the results obtained with thorium-234.

Thorium was extracted completely from solutions that contained the radi-tracer and 20 micrograms of carrier when the concentration of nftric acid was varied from 0.5 to $3 \mathrm{M}$.

Extraction of Uranium

Quantitative extraction of tetravalent uranium from acidic solutions with TOPO is difficult to achleve because oxidation of uranium(IV) to uranium(VI) occurs to varying extents during equilibration. Conversion to the hexavalent state is rapid and essentially quantitative in nitric acid media, nearly complete in sulfuric acid solutions and relatively slow in hyörochloric acid systems. Consequently, uranium is extracted from nitrate solutions as the uranyl species only, while mixtures of tetraand hexavalent uranium species are extracted from sulfate and chloride media unless uranium is maintained in the tetravalent state by removal of air from the system (Figure 45).

Uranium(VI) is readily extracted from acid nitrate or chloride solutions and, to a lesser extent, from acid sulfate or perchlorate media (Figure 46). Extremely high extraction coefficients are obtained from acidic solutions which are $1 M$ in nitrate or 2 to $10 \underline{M}$ in chloride. The extraction of uranium decreases when the concentration of nitric acid is increased due to the co-extraction of the mineral acid. Quantitative extraction cannot be attained from sulfuric acid solutions; however, the extraction is markedly increased by the addition of nitric or hydrochloric acid or salts of these acids. Extraction of uranium from nitrate or chloride solutions is essentially instantaneous; however, extractions are generally carried out for 5 to 10 minutes. The degree of extraction is decreased slightly when the aqueous/organic phase ratio is increased above 1 (Figure 47). 


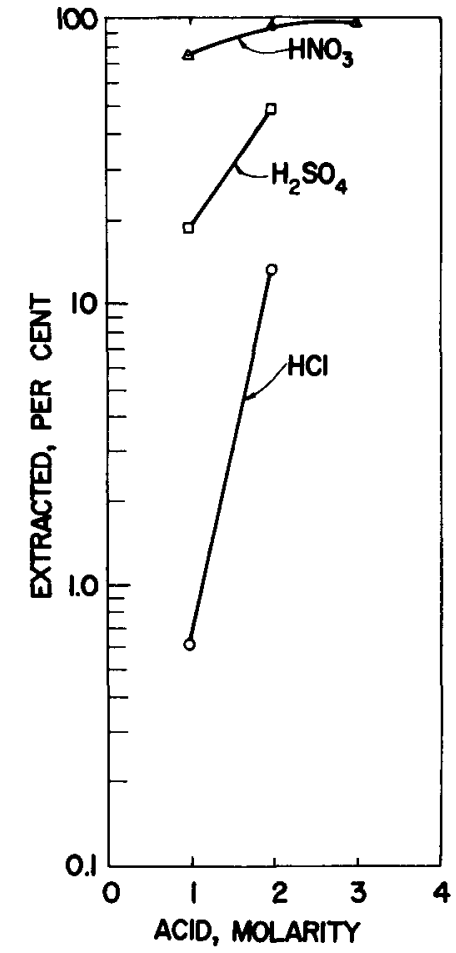

FIGURE 45. EXTRACTION OF URANIUM WITH TRI-N-OCTYIPHOSPHINE OXIDE FROM URANIUM(IV) SOLUTIONS. Uranium(IV) - $17 \mathrm{mg}$; TOPO - $0.1 \mathrm{M}$ in cyclohexane, $5 \mathrm{ml}$; Phase ratio1 ; and Extraction time - 10 minutes.

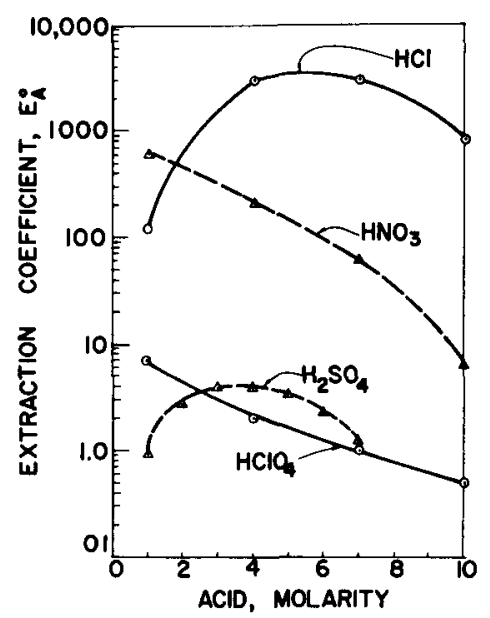

FIGURE 46. EXTRACTION OF URANIUM (VI) WITH TRI-N-OCTYLPHOSPHINE OXIDE AS A FUNCTION OF ACID CONCENTRATION. Uranium - 9 mg; TOPO $0.1 \mathrm{M}$ in cyclohexane, $5 \mathrm{ml}$; Phase ratio - 1; and Extraction time 10 minutes.

The species extracted from chloriōe and nitrate solutions are $\mathrm{UO}_{2} \mathrm{Cl}_{2} \cdot$ $2(\mathrm{TOPO})$ and $\mathrm{UO}_{2}\left(\mathrm{NO}_{3}\right)_{2} \cdot 2(\mathrm{TOPO})$. As much as $19 \mathrm{mg}$ of uranium is extracted in excess of 98 per cent by 0.5 millimole of TOPO from $1 \mathrm{M} \mathrm{HCl}$, while $40 \mathrm{mg}$ of uranium can be extracted from $1 \underline{\mathrm{M}} \mathrm{HNO}_{3}$ to an extent that exceeds 99 per cent in a single extraction (Figure 48). The stoichiometric saturation value, $60 \mathrm{mg}$, of uranium can be 95 per cent attalned with $5 \mathrm{ml}$ of $0.1 \mathrm{M}$ TOPO in cyclohexane when the aqueous phase contains three-fold excess uranium $(\sim 200 \mathrm{mg})$.

The extractability of uranium(VI) from weakly acid phosphate solutions has been investigated with solutions of $0.6 \mathrm{M}$ TOPO in kerosene. (1) Results from these studies have shown that the extraction coefficient of uranium is very low in phosphate systems and decreased with increasing pH (Figure 49), or increasing phosphate concentration (Figure 50). 


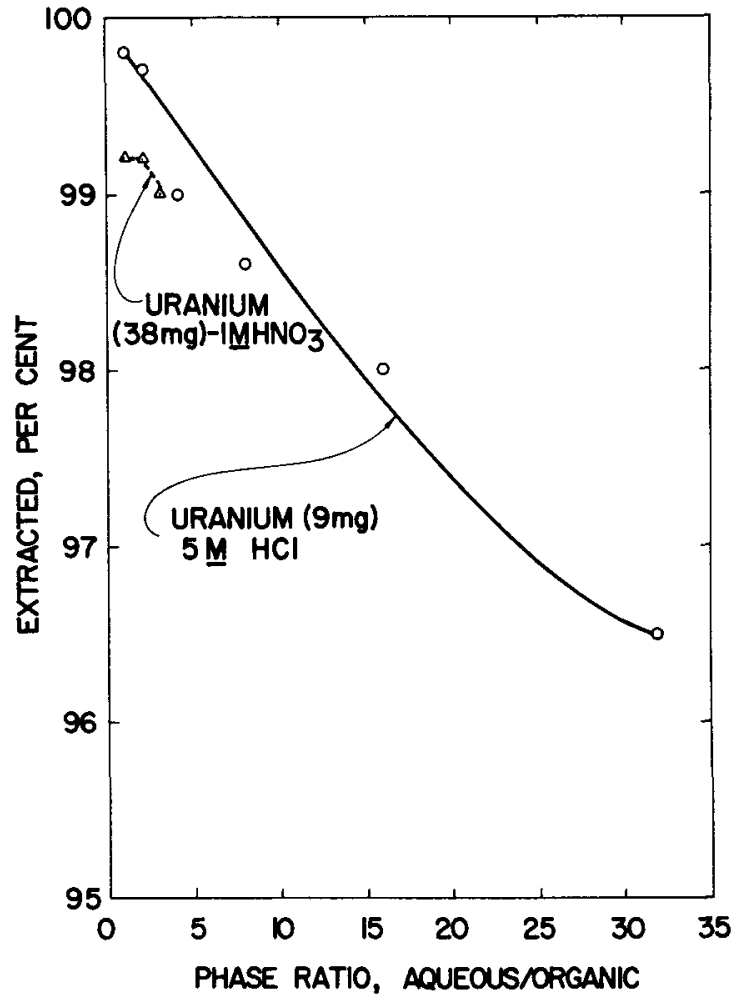

FIGURE 47. EXIRACTION OF URANIUIS(VI) ITTEA TRI-N-OCTYLPHOSPHTTE OXIDI AS $\Lambda$ FUNGCTON OF PHASE RATIO. TOPO - $0.1 \mathrm{MI}$ in cyclohexane, $5 \mathrm{ml}$ and Extraction time $=10$ minutes.

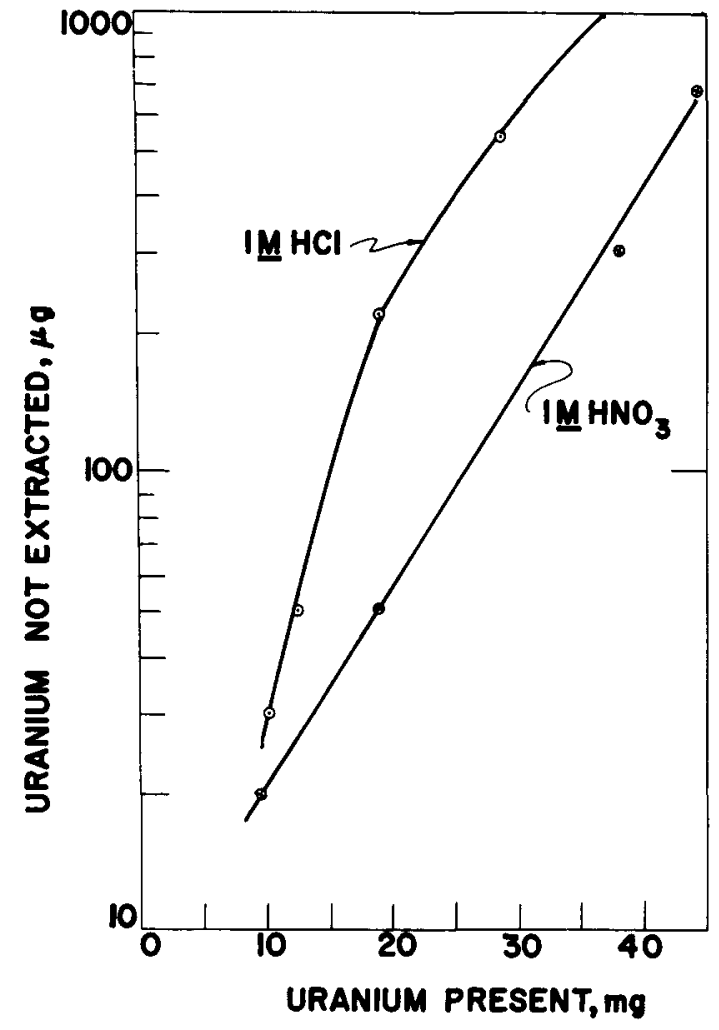

FIGIRE L8. EXTRACTION OF URANIUI ITH TRI-T-OCTLLPIOSPHTTE OXIDE. TOPO - 0.1 II in cyclohexane, $5 \mathrm{ml}$; Phase ratio - 1 , and Equilibration time, 10 minutes. 


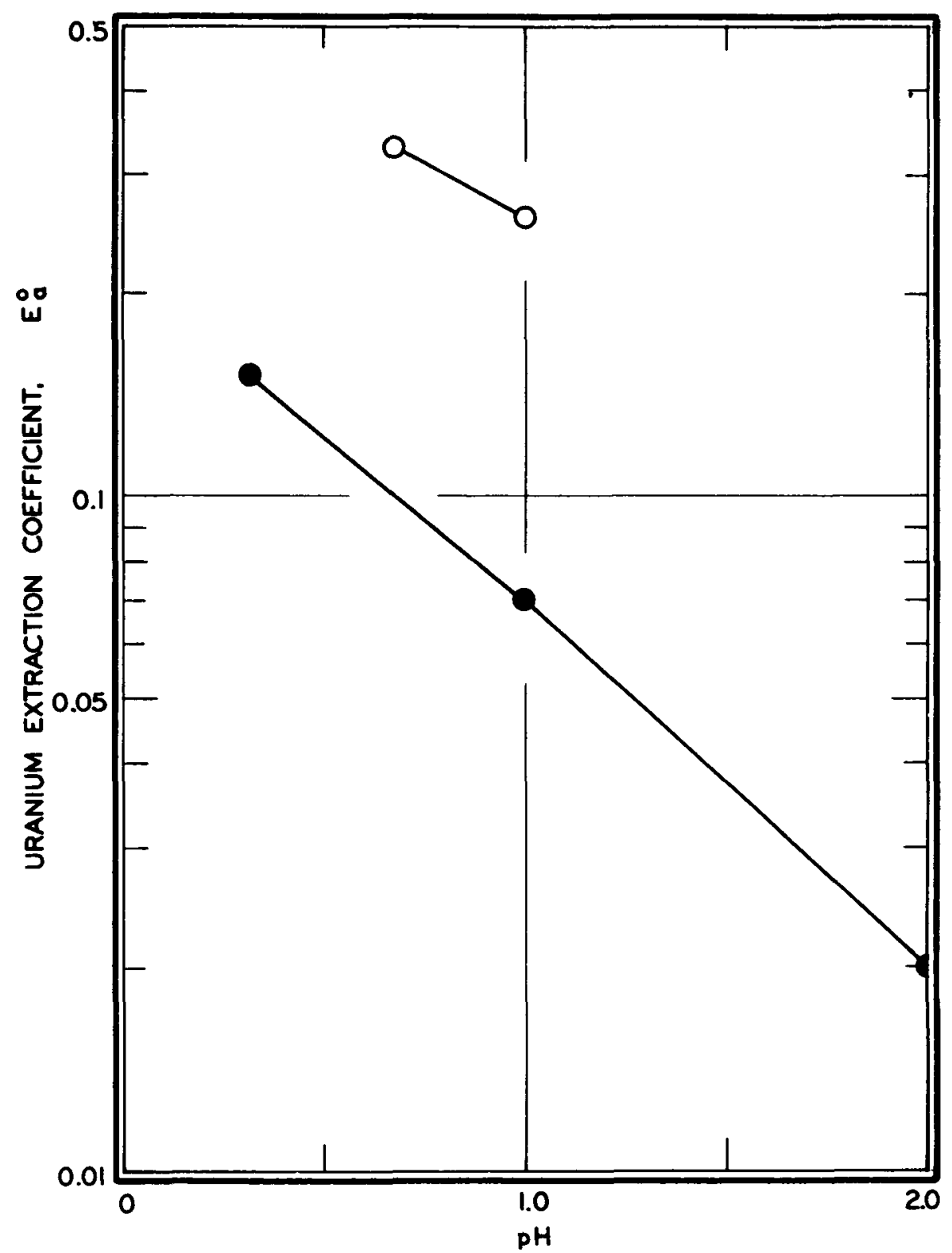

FIGURE 49. URANIUM EXTRACTION FROM PHOSPHATE SOLUTION EFFECT OF PH LEVEL

TOPO - $0.6 \mathrm{M}$ in kerosene

Phase ratio- aqueous/organic, 2

$\begin{array}{ll}0 & 0.004 \mathrm{M} \mathrm{U}(\mathrm{VI}), 1.4 \mathrm{M} \mathrm{PO}_{4} \\ 0.0004 \mathrm{MU}(\mathrm{VI}), 3.3 \mathrm{M} \mathrm{PO}_{4}\end{array}$ 


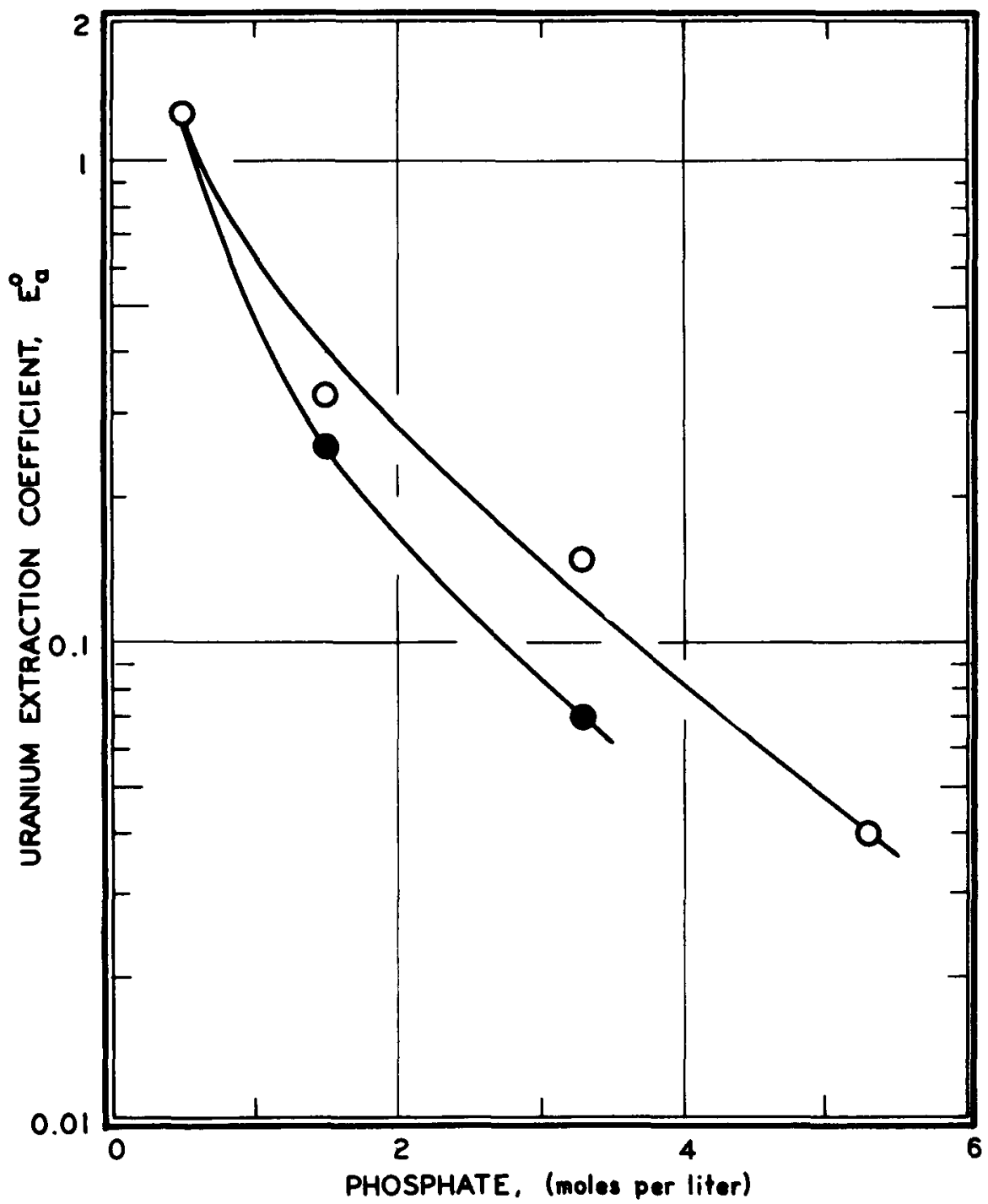

FIGURE 50. URANIUM EXIRACTION FROM PHOSPHATE SOLUTION EFFECT OF PHOSPHATE CONCENTRATION

TOPO - $0.6 \mathrm{M}$ in kerosene

Phase ratio- aqueous/organic, 2

Uranium -0.0004 and $0.004 \mathrm{M}$

O- $\mathrm{pH}$ of unbuffered $\mathrm{H}_{3} \mathrm{PO}_{4}$

- $\mathrm{pH} 1$ 


\section{Extraction of Transuranic Elements}

The extraction characteristics of neptunium, plutonium, and americium have been investigated with TOPO in solutions of Amsco 125-82 by Weaver, Horner, and Coleman. $(5,6,13)$ Martin and Ockenden ${ }^{(8)}$ used cyclohexane solutions of TOPO in their examination of the extraction of plutonium and americium.

Neptunium. (13) The partitioning of neptunium(IV) between acid nitrate or sulfate solutions and $0.01 \mathrm{M}$ and $0.1 \mathrm{M}$ solutions of TOPO in Amsco 125-82 was followed by radiometric measurement of the 50-hour gamma activity of neptunium-238. Extraction maxima are obtained in $1 \underline{M}$ and $8 \underline{M}$ $\mathrm{HNO}_{3}$ (Figure 5I), and the extraction is enhanced significantly by substitution of neutral nitrate salts for nitric acid. Substitution of sulfate, especially neutral sulfate salts, for nitrate causes the extraction to be severely decreased as shown in Table VI.

\section{TABLE VI}

EXTRACTION OF NEPTUNIUM(IV) FROM SULFATE SOLUTIONS

\begin{tabular}{|c|c|c|c|}
\hline \multicolumn{3}{|c|}{ Normality } & \multirow{2}{*}{$E_{a}^{\circ}$} \\
\hline TOPO & $\mathrm{H}_{2} \mathrm{SO}_{4}$ & $\mathrm{Na}_{2} \mathrm{SO}_{4}$ & \\
\hline 0.1 & $\begin{array}{l}4.5 \\
2.0 \\
0.10 \\
1.0 \\
1.0 \\
1.0 \\
2.0\end{array}$ & $\begin{array}{c}- \\
2.5 \\
4.4 \\
- \\
1.0 \\
3.5 \\
-\end{array}$ & $\begin{array}{l}1.1 \\
0.06 \\
0.004 \\
0.34 \\
0.13 \\
0.013 \\
0.46\end{array}$ \\
\hline
\end{tabular}

Pentavalent neptunium is extracted only partieliy ( 50 per cent) from 2 and $8 \mathrm{M} \mathrm{HNO}_{3}$ with $0.3 \mathrm{M}$ TOPO in Amsco.

Plutonium. In their extensive study of the extraction of plutonium(III, IV, and VI), Martin and Ockenden found that tetra- and hexavalent plutonium species are-readily extracted from acid chloride (Figure 52) or acid nitrate solutions (Figure 53). Plutonium(IV) is extracted from nitrate solutions as $\mathrm{Pu}\left(\mathrm{NO}_{3}\right)_{4} \cdot 2(\mathrm{TOPO})$, and the extraction is most favorable from 6 tc $7 \underline{\mathrm{M}} \mathrm{HNO}_{3}$ or 9 to $10 \underline{\mathrm{M}} \mathrm{HCl}$ media. (8) In their investigations, Homer and Coleman found that maximum extraction of plutonium(IV) occurs from I $\mathrm{M} \mathrm{HNO}_{3}$, decreases as the acidity is raised to 


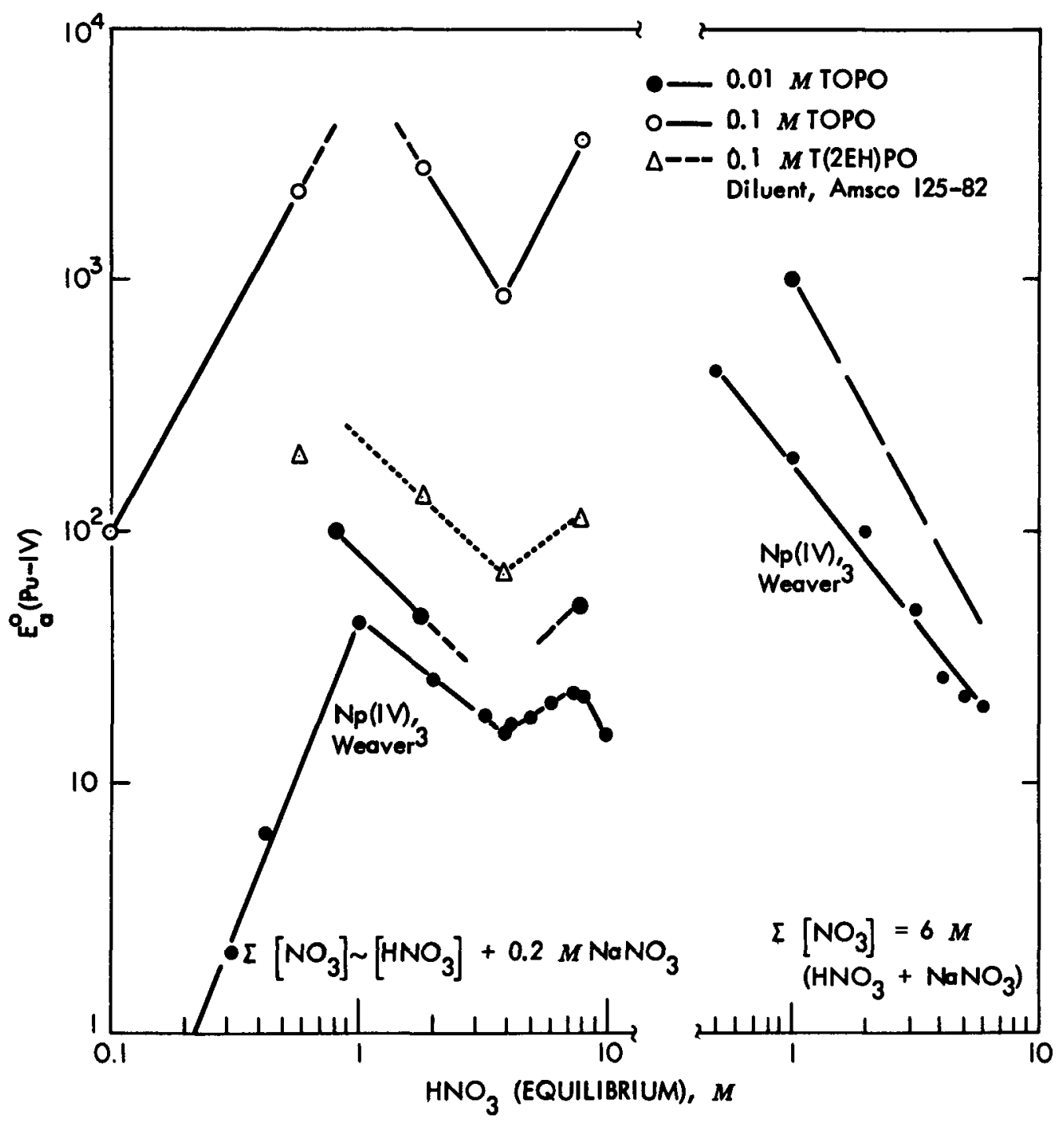

FIGURE 51. PLUTONIUM(IV) EXTRACTION BY TRI-N-OCTYLPHOSPHINE OXIDE AND TRI-(2-ETHYLHEXYL) PHOSPHINE OXIDE: EFFECT OF NITRIC ACID AND SODIUM NIIRATE CONCENIRATIONS. PLUTONIUM(IV) STABILIZED WITH $0.04-0.1$ M $\mathrm{NaNO}_{2}$. 


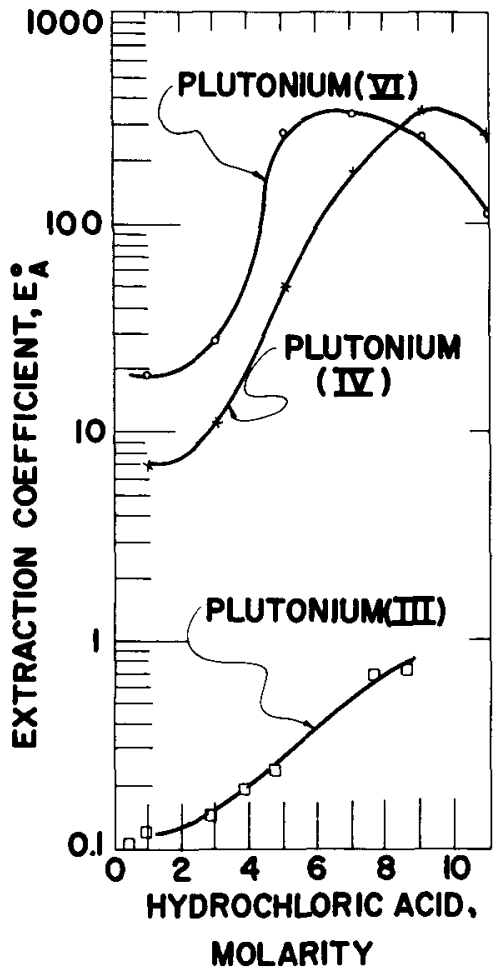

FIGURE 52. EXTRACTION OF PLUTONIUM FROM HCI WITH TRI-N-OCTYLPHOSPHINE OXIDE. TOPO $-0.1 \mathrm{M}$ in cyclohexane; Phase ratio - 1; and Extraction time - 10 minutes.

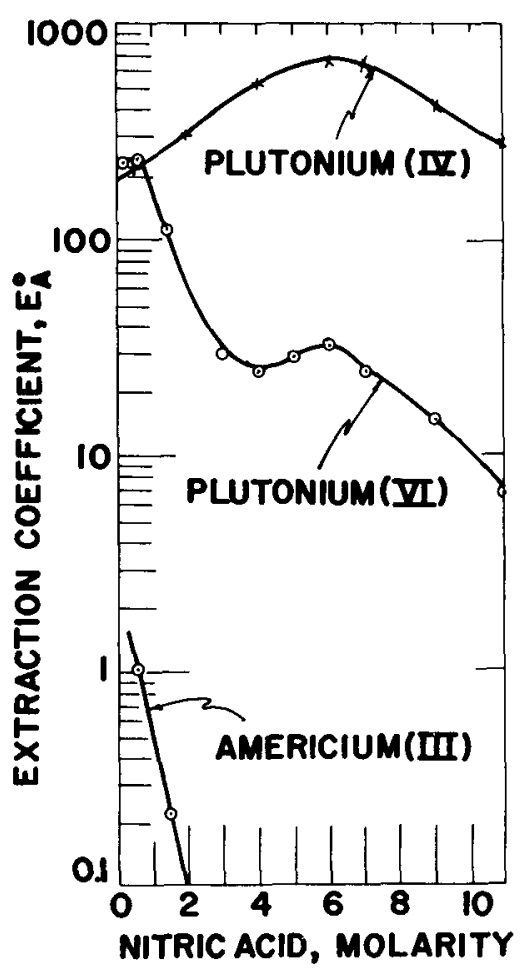

FIGURE 53. EXTRACTION OF PLUTONTIM AND A VERT CI ITM FROM HNOO 3 SOLITTIONS. TOPO $0.1 \mathrm{M}$ in cyclohexane; Phase ratio - J.; and Extraction time - 10 minutes.

$4 \mathrm{M}_{\mathrm{NNO}}$, and then increases again in highly acid systems (Figure 51).

Extraction coefficients greater than 100 are achieved with $0.1 \mathrm{M}$ TOPO in Amsco throughout the entire acid region studied and exceed 1000 under the most favorable conditions. (6) The extraction of plutonium(IV) is also enhanced when a nitrate salt is substituted for nitrin acid.

Martin found that plutonium(VI) is extracted most favorably. from $<1 \underline{\mathrm{M}} \mathrm{ENO}_{3}$ or $7 \underline{\mathrm{M} H C l}$ solutions and the ratio of TOPO/metel in the extracted species is 2. (8) Horner observed that the extraction of plutonium(VI) is lower than that of plutonium(IV) by a factor of 10; coefficients of 320 and 17 are obtained in 2 and $4 \mathrm{M} \mathrm{HNO}_{3}$ systems.

The extraction coefficients of plutonium(III) are much lower than those exhibited by plutonium(IV) and (VI) in nitric acid systems. Martin reports coefficients less than unity (Figure 53), while Horner ${ }^{(6)}$ found coefficients 
of $\sim 3$ in $0.5 \underline{M}$ and $2 \underline{\mathrm{M}} \mathrm{HNO}_{3}$ and $\sim 2$ in $6 \underline{\mathrm{M}} \mathrm{HNO}_{3}$. The bighly variable results, coefficients of $<1$ to $>100$, obtained in trivalent plutonium systems are attributed to oxidation of plutonium(III) during equilibration of the phases.

Plutonium is only partially extracted from sulfurlc acid solutions and the extraction is decreased further when a sulfate salt is substituted for sulfuric acid, as is shown in Table vrI. $(5,6)$

\section{TABLE VII}

EXTRACTION OF PLUTONIUM FROM SULFATE SOLUTIONS

TOPO, $\frac{\mathrm{Normality}}{\mathrm{H}_{2} \mathrm{SO}_{4} \quad\left(\mathrm{NH}_{4}\right)_{2} \mathrm{SO}_{4}}$

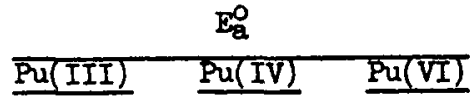

0.1

$$
6
$$

4.4

0.4

1.0

5.0

-

0.01

$-\quad<0.01$

0.3

$$
10
$$

1.6

4.4

20

0.1

Martin and Ockenden observed that the specles of plutonium(IV) and (VI) that are extracted from nitric acid exhibit spectra that closely resemble those of the corresponding aqueous solutions of plutonium(IV and VI) nitrate. The plutonium(IV) adduct absorbs light at 491 millimicrons and, to a lesser extent, at $550,660,715$, and 790 millimicrons; maximum absorbance of the plutonium(VI) adduct is exhibited at 847 millimicrons, while very little light is absorbed at lower wavelengths.

Extracted plutonium(IV) can be stripped completely by $0.1 \underline{\mathrm{M} \mathrm{Na}} \mathrm{Na}_{3}$ solution at a phase ratio of $1 / 1$. (5)

Americium is extracted poorly from acid nitrate solutions. Martin and Ockenden $(8)$ found that the extraction decreased continualiy as the concentration of nitric acid was increased (Figure 53). Weaver et al observed the same trend and report somewhat higher extraction coefficients in $0.3 \mathrm{M}$ TOPO systems, 1.e. $\mathrm{F}_{\mathrm{a}}^{\circ}$ equivalent to 17 and 1.0 in $0.2 \mathrm{M}$ and $2 \mathrm{M}$ $\mathrm{HNO}_{3}$ systems. (13) 


\section{APPANDIX I}

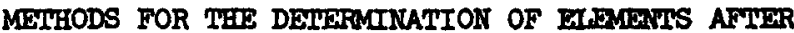

EXIRACTION WITH TRI-N-OCTYIPPHOSPHINE OXIDE

A. Young, J. P. and J. C. White, "Bxtraction of Titanlum Thlocyanate with Tri-n-octylphosphine Oxide - Direct Colorimetric Determination in the Organic Phase," Anal. Chem. 31, 393 (1959).

B. Mann, C. K. and J. C. White, "Extraction of Chromilue with Trioctylphosphine Oxide from Acidic Solutions of Alkall Metal Salts - Determination in Situ as Chromium-Diphenylcarbazide Complex," Anal. Chem. 30, 989 (1958).

C. Apple, R. F. and J. C. White, "Extraction of Iron with Tri-n-octy1phosphine Oxide and Determination in Situ as the Ferrous-1,10 phenalthroline Complex," unpublished report.

D. Young, J. P. and J. C. White, "The Extraction of Zirconilum with Tri-noctylphosphine Oxide and Its Direct Determination in the Organic Phase with Pyrocatechol Violet," Talanta 1, 263 (1958).

E. Ross, W. J. and J. C. White, "Bxtraction of Molybdenum with tri-noctylphosphine Oxide and Its Determination in Organic Media with Thioglycolic Ac1d," unpublished report.

F. Ross, W. J. and J. C. White, "Extraction of Tin with Tris(2-ethylhexyl) phosphine Oxide and Its Determination in Non-Aqueous Medium with Pyrocatechol Violet," Anal. Chem. 33, (March 1961).

G. White, J C. and R. F. Apple, "The Spectrophotometric Determination of Cerium in Fluoride Salts," Talanta 2, 176 (1959). 
H Ross, W. J. and J. C. White, "Extraction and Determination of Thorium from Sulfate and Phosphate Solutions with Tri-n-octylphosphine Oxide," Anal. Chem. 31, 1847 (1959).

I. Horton, C. A. and J. C. White, "Separation of Uranium by Solvent Extraction with Tri-n-octylphosphine Oxide - Direct Colorimetric Determination with Dibenzoylmethane," Anal. Chem. 30, 1779 (1958).

J. Ross, W. J. and J. C. White, 'Direct Spectrophotometric Determination of Uranium in Cyclohexane Solutions of Tri-n-octylphosphine Oxide," unpublished data.

K. J. C White, "The Use of Trialkylphosphine Oxides as Extractants in the Fluorometric Determination of Uranium," ORNL-2161, November, 1956.

L. Dietrich, W. C., J. D. Caylor, E E. Johnson, "Separation of Uranium from Urine by a Tri-n-octylphosphine Oxide Column and an Automation of the Procedure," Y-1322, September, 1960. 


\section{REFERENCES}

1. Blake, C. A., K. B. Brown, and C. F. Coleman, "Solvent Extraction of Uranium (and Vanadium) from Acid Liquors with Trialkylphosphine Oxides," Oak Ridge National Laboratory Report ORNL-1964, August, 1955.

2. Boyd, G. E. and Q. V. Larson, J. Phys. Chem. 64, 988 (1960).

3. Brown, K. B., C. F. Colemen, D. J Crouse, and A. D. Ryon, "Progress Report on Raw Materials for April, 1957," p. 14, ORNL-2346, July, 1957.

4. Gilbert, T. W., Jr., "Analytical Chemistry Division Annual Progress Report for Period Ending December 31, 1957," ORNL-2453, p. 66.

5. Horner, D. E. and C. F Coleman, "Recovery of Uranium and Plutonium from Sulfuric Acid Decladding Systems," ORNL-2830, November, 1959.

6. Horner, D. E. and C. F. Coleman, "Plutonium Extraction from Nitrate and Sulfate Solutions by Amines and Organophosphorus Compounds," ORNL-3051, February, 1961.

7. Horton, C. A., "Anelytical Chemistry Division Annual Progress Report for Period Ending December 31, 1958," ORNL-2662, p. 61 .

8. Martin, B. and D. W. Ockenden, "The Solvent Extraction of Plutonium and Americium by. Tri-n-octylphosphine Oxide," United KIngdom Atomic Energy Commission, PG Report 165 (W), 1960.

9. Moore, F. L., Anal. Chem. 28, 997 (1956).

10. Ross, W. J. and J. C. White, "The Solvent Extraction of Iron with Trin-octylphosphine Oxide," ORNL-2382, September, 1957.

11. Ross, W. J. and J. C. White, "The Use of Tri-n-ctylphosphine Oxide in the Solvent Extraction of Thorium from Acidic Solutions," ORNL-2627, November, 1958. 
12. Schmitt, J. M., Oak Ridge National Laboratory, unpublished data.

13. Weaver, B. and D. E. Horner, J. Chem. Eng. Date 5, 260 (1960).

14. Weaver, B., unpublished data.

15. White, J. C and W. J. Ross, "The Use of Tri-octylphosphine Oxide in the Solvent Extraction of Zirconium," ORNL-2498, April, 1958.

16. White, J. C. and W. J. Ross, "Extraction of Chromium with Trioctylphosphine Oxide," ORNL-2326, July, 1957.

17. Zingaro, R. A. and J. C. White, J. Inorg. Nucl. Chem. 12, 315 (1960). 